Review

\title{
Does perceived overweight increase risk of depressive symptoms and suicidality beyond objective weight status? A systematic review and meta- analysis
}

\author{
Ashleigh Haynes $^{\mathrm{a}, *}$, Inge Kersbergen ${ }^{\mathrm{b}}$, Angelina Sutin ${ }^{\mathrm{c}}$, Michael Daly ${ }^{\mathrm{d}, \mathrm{e}}$, Eric Robinson ${ }^{\mathrm{f}}$ \\ ${ }^{a}$ Centre for Behavioural Research in Cancer, Cancer Council Victoria, Melbourne, Australia \\ ${ }^{\mathrm{b}}$ School of Health and Related Research, University of Sheffield, UK \\ ${ }^{\mathrm{c}}$ Florida State University College of Medicine, United States of America \\ ${ }^{\mathrm{d}}$ Department of Psychology, Maynooth University, Co. Kildare, Ireland \\ ${ }^{\mathrm{e}}$ UCD Geary Institute, University College Dublin, Ireland \\ ${ }^{\mathrm{f}}$ Department of Psychological Sciences, University of Liverpool, Liverpool, UK
}

\section{H I G H L I G H T S}

- Perceived overweight was associated with increased depression and suicidality in this systematic review and meta-analysis

- Weight perception also explained the relationship between BMI and mental health

- Results were consistent across multiple subgroup and sensitivity analyses

- However, heterogeneity and the inclusion of only observational data limit the strength of conclusions

- Results highlight the importance of the psychological experience of overweight in mental health

\section{A R T I C L E I N F O}

\section{Keywords:}

Depression

Suicide

Meta-analysis

Perceived overweight

Obesity

\begin{abstract}
A B S T R A C T
Obesity is associated with a significant disease burden, but whether recognising as opposed to failing to recognise personal overweight is beneficial or detrimental to mental health is unclear. Here we examine the associations between perceived overweight and depressive symptoms and suicidality. A systematic search of three electronic databases yielded 10,398 unique records, from which 32 studies (110 observations) were eligible for inclusion. Pooled odds ratios (OR) and 95\% confidence intervals (CI) were calculated for each outcome using random effects meta-analyses and potential publication bias was examined. Perceived overweight was associated with an increased risk of depressive symptoms (OR: 1.42 , CI: $1.31,1.54 p<.0001, N>128,585$ ) and suicidality (OR: 1.41 , CI: $1.28,1.56, p<.0001, N=133,576$ ) in both cross-sectional and longitudinal studies. The association between perceived overweight and poorer mental health was observed irrespective of study origin, participant age (children vs. adults), gender, and whether or not a person was objectively overweight. The pooled statistical relationship between objective weight status and poorer mental health was attenuated to non-significance when perceived overweight was accounted for, suggesting that the detrimental effect of overweight on mental health is largely dependent on whether or not a person identifies as overweight.
\end{abstract}

\section{Introduction}

Overweight and obesity are associated with an increased risk of non-communicable diseases such as cardiovascular disease, type 2 diabetes, osteoarthritis, and some cancers, presenting a significant worldwide health burden (Kelly, Yang, Chen, Reynolds, \& He, 2008; Must et al., 1999; The Global Burden of Disease 2015 Obesity
Collaborators, 2017). The nature of the association between overweight or obesity and mental health, however, is less clear. Many reviews and meta-analyses have indicated an association between overweight or obesity and increased risk of mental health problems, but these relationships are complex (Atlantis \& Baker, 2008; Faith et al., 2011; Friedman \& Brownell, 1995; Heneghan, Heinberg, Windover, Rogula, \& Schauer, 2012; Luppino et al., 2010; Mannan, Mamun, Doi, \&

\footnotetext{
* Corresponding author at: Centre for Behavioural Research in Cancer, Cancer Council Victoria, St Kilda Road, Melbourne, VIC 3004, Australia.

E-mail address: Ashleigh.haynes@cancervic.org.au (A. Haynes).
} 
Clavarino, 2016). Some evidence suggests that obesity increases risk of depression and suicidality in women but is unrelated or protective in men (Luo et al., 2018; Vittengl, 2018; Zhang, Yan, Li, \& McKeown, 2013), and in some ethnic groups but not others (BeLue, Francis, \& Colaco, 2009; Eaton, Lowry, Brener, Galuska, \& Crosby, 2005). Others have found weak evidence for the association between obesity and mental health (Atlantis \& Baker, 2008; Perera et al., 2016), or suggest a 'U-shaped' function describing the relationship between BMI and depression risk (de Wit, van Straten, van Herten, Penninx, \& Cuijpers, 2009). Further, while some research has demonstrated a bidirectional longitudinal relationship between higher BMI and the development of depression (Hasler et al., 2005; Luppino et al., 2010), recent evidence from research using Mendelian randomisation suggests that higher BMI may be causally related to the development of depression, whereas depression may not increase risk of gaining weight (van den Broek et al., 2018; Wray et al., 2018). Given the high prevalence of overweight and obesity (Kelly et al., 2008; World Health Organization, 2016) and the negative impacts of poor mental health (Kessler et al., 2011; Murray \& Lopez, 1996), understanding the relationship between overweight and obesity and risk of mental health problems is of importance.

A substantial proportion of individuals with overweight or obesity fail to accurately identify their weight status (Foti \& Lowry, 2010; Johnson, Cooke, Croker, \& Wardle, 2008; Robinson, 2017; Robinson \& Oldham, 2016), and this factor could explain some variation in mental health outcomes associated with overweight and obesity. A failure to accurately self-identify as 'overweight' has traditionally been viewed as problematic, as it is thought to deter weight loss (Brug, Wammes, Kremers, Giskes, \& Oenema, 2006; Duncan et al., 2011). This assumption has foundations in traditional theories of health behaviour and motivation. For example, the Health Belief Model proposes that perceived susceptibility to a health problem motivates behaviour change to mitigate that risk (Janz \& Becker, 1984), and Self-Discrepancy Theory posits that individuals are motivated to attain a match between how they perceive themselves ('self-concept') and a personally-relevant or societal standard representing the 'ideal' self, or what they 'ought' to be (E. T. Higgins, 1987; Vartanian, 2012). In the case of self-identification of overweight, it is assumed that recognition of a discrepancy between one's current status as being categorised as overweight ('self-concept') and the societal standard of having a 'normal' or healthy weight will motivate an individual to resolve that discrepancy. As a result, there is a focus in public health and policy spheres on fostering awareness of personal weight status to promote weight loss (Moyer, 2012; NICE, 2014). However, while there is strong evidence to suggest that individuals who perceive themselves as overweight are more likely to attempt weight loss, recent prospective studies suggest that these individuals are actually at increased risk of overeating and weight gain (Haynes, Kersbergen, Sutin, Daly, \& Robinson, 2018; Robinson, Hunger, \& Daly, 2015; Sutin \& Terracciano, 2015), and the effectiveness of interventions notifying individuals of their weight status for promoting weight loss is questionable. In a quasi-experimental study in public schools in New York City, female students with a BMI that just exceeded the threshold for being labelled as 'overweight' (and who were informed of this classification) were compared to students who fell just below this threshold (who therefore had similar BMIs but were not classed as 'overweight'). Contrary to the aim of the program, being labelled as 'overweight' was not associated with a decrease in weight in the following year (Almond, Lee, \& Schwartz, 2016). Similar results were found among Korean adults participating in a national health screening program (H. Kim, Lee, \& Lim, 2017).

One potential explanation for these seemingly divergent findings and for the effect of overweight on poor mental health, is that overweight and obesity are widely stigmatised (Puhl \& Brownell, 2001, 2006). Experiencing discrimination based on weight has been shown to explain the association between obesity and poor psychological wellbeing (Carr \& Friedman, 2005; Jackson, Beeken, \& Wardle, 2015;
Robinson, Sutin, \& Daly, 2016). Individuals who identify as overweight may experience social identity threat stemming from weight stigma, such that they experience concern over or anticipate being devalued or negatively stereotyped because of their weight (Hunger, Major, Blodorn, \& Miller, 2015). This may in turn result in physiological stress and impair self-regulation of weight-related behaviours such as eating and physical activity (Himmelstein, Incollingo Belsky, \& Tomiyama, 2014; Hunger et al., 2015; Major, Eliezer, \& Rieck, 2012; Schvey, Puhl, \& Brownell, 2011; Tomiyama, 2014). In addition, the adverse mental health effects that have been shown to be associated with weight stigma (Papadopoulos \& Brennan, 2015; Puhl \& Suh, 2015) have also been demonstrated to promote weight gain (Blaine, 2008; Luppino et al., 2010), meaning that identifying as overweight may be detrimental for weight outcomes rather than promoting weight loss. Importantly, these effects arise because an individual need not objectively belong to a stigmatised group to experience the negative consequences of stigma, but merely perceiving oneself as having a stigmatised identity may be sufficient (Hunger et al., 2015; Schmitt, Branscombe, Postmes, \& Garcia, 2014; Tomiyama, 2014). It follows then, that the adverse mental health effects that have been shown to be associated with overweight and obesity may not depend primarily on an individual's objective weight status, but rather, whether or not they perceive themselves as belonging to the stigmatised group.

There is now a body of observational evidence suggesting that personal identification of overweight and obesity regardless of one's objective weight status may be associated with depression (including clinically-diagnosed depression or symptoms including low mood, hopelessness, anhedonia, fatigue, difficulty concentrating) and suicidality (i.e., suicidal ideation or attempted suicide). For example, in one study US adolescents who perceived themselves as overweight were more likely to have major depression than those who perceived themselves as having a normal weight (Roberts \& Duong, 2013). Perceived overweight has also been shown to be associated with suicidal ideation in Korean adolescents (D. S. Kim, Cho, Cho, \& Lim, 2009), and with increases in depressive symptoms at 7-year follow up in a prospective population-based survey of US adults (Daly, Robinson, \& Sutin, 2017). However, another prospective study showed that perceived overweight at baseline was unrelated to depressive symptoms one year later (Lo et al., 2009). There are also some mixed findings by gender, which are consistent with the greater value placed on physical appearance in women than in men (Fredrickson \& Roberts, 1997; McKinley, 1998). For example, Korean women categorised as having a 'normal' weight who misperceived themselves as overweight were more likely to experience suicidal ideation, however this was not observed in men (Shin et al., 2015). Similarly, studies on adolescents in China and the US found that only female adolescents who perceived themselves as overweight were at higher risk of depressive symptoms relative to those with perceived normal weight, whereas male adolescents were not (Yuan, 2007; Zhao et al., 2012), and the same pattern was found in a prospective study predicting suicidal ideation at one year follow-up in US adolescents (Seo \& Lee, 2013). However, in other studies perceived overweight has been associated with worse mental health among males (Frisco, Houle, \& Martin, 2010; D. S. Kim et al., 2009). Importantly, the effects discussed here were all observed when objective BMI or weight status was taken into account. Perceived weight may also differentially impact mental health depending on objective weight status. For Korean adolescents with normal weight, inaccurately viewing oneself as 'overweight' was associated with a higher risk of depressive symptoms but there was no elevated risk associated with accurately perceived overweight (Byeon, 2015). These findings run contrary to evidence from a prospective study of US adolescents with overweight or obesity demonstrating that those who accurately identified themselves as 'overweight' were at a higher risk of experiencing depressive symptoms in adulthood (Thurston et al., 2017). Thus, at present the extent to which personal identification of overweight is predictive of mental health problems, and whether the accuracy of this perception or a 
person's age or gender determine the association, is unclear.

Understanding whether and for whom identifying as overweight is associated with mental health problems is important, and will contribute to the consideration of the potential mental health costs of interventions promoting awareness of personal weight status (Moyer, 2012; NICE, 2014). The aim of the present systematic review and metaanalysis was to examine the relationship between self-perceived overweight and mental health. We focused on depressive symptoms and suicidality as key measures of mental health problems because of the number of studies studying these variables and weight perception now available. We aimed to examine whether there was evidence of both a cross-sectional and prospective association between perceived overweight and both depressive symptoms and suicidality, whether this association was observed in both adults and children, and whether the association depended on gender and accuracy of weight perception. Given that there is some evidence of cultural differences in the stigma associated with obesity (Brewis, Wutich, Falletta-Cowden, \& RodriguezSoto, 2011; Crandall et al., 2001; Crandall \& Martinez, 1996) and the prevalence of overweight and obesity varies across geographical regions (e.g., worldwide overweight and obesity prevalence is $52 \%$ in adults and $18 \%$ in children/adolescents; versus $67 \%$ and $21 \%$ in USA, and $32 \%$ and $12 \%$ in China, World Health Organization, 2016), we therefore examined whether the association between perceived overweight and mental health differed based on study origin. We also theorize that the relationship between objective overweight and poorer mental health may primarily depend on whether or not a person recognises that they are categorised as overweight.

We hypothesised that individuals who perceived themselves as overweight would have higher odds of depressive symptoms and higher odds of suicidality compared to those who did not, in both cross-sectional and prospective studies. Given the mixed evidence to date, we did not have formal hypotheses about potential differences between subgroups separated by gender, study origin, accuracy of weight perception, or age. Moreover, in line with previous work we predicted that objective overweight would be associated with higher risk of depressive symptoms and suicidality (Heneghan et al., 2012; Pereira-Miranda, Costa, Queiroz, Pereira-Santos, \& Santana, 2017; Quek, Tam, Zhang, \& Ho, 2017), but that the relationships between weight status and mental health problems would be attenuated when accounting for self-perception of overweight; evidence which would suggest that the demonstrated association between overweight and poorer mental health is dependent on whether or not a person recognises that they are overweight

\section{Methods}

Review methodology was guided by the Preferred Reporting Items for Systematic Reviews and Meta-Analyses (PRISMA, Moher, Liberati, Tetzlaff, \& Altman, 2009) and was pre-registered with the International Prospective Register of Systematic Reviews (PROSPERO registration number CRD42017077357). Minor deviations from and additions to the pre-registered analysis plan are summarised in Appendix C, online supplemental materials.

\subsection{Eligibility criteria}

We included studies that examined the association between perceived weight status and either depression (including depressive symptoms, diagnosis of depressive disorder) or suicidality (including suicidal thoughts, behaviours, intent, or attempts). Perceived weight indicators were required to include a comparison between individuals who perceived themselves as overweight and those who did not (e.g., perceived normal or healthy weight, or a combination of individuals with perceived normal or underweight). Studies were included if they were available in English and published in peer-reviewed articles from 1991 onwards. We decided to focus on studies conducted from 1991 onwards (producing a review of $\geq 25$ years of research) as we believed results prior to this may not be representative and the majority of the research we were aware of was conducted after this date. We applied the following exclusion criteria: clinical (e.g., patients with schizophrenia) or non-general samples (e.g., pregnant women only), assessment of perceived weight status where it was unclear whether participants identified themselves as 'overweight' (e.g. pictorial scales without weight status labels as participants' perceptions of the weight status of the figures, and therefore the label with which they describe their own weight status could not be verified), analyses of perceived weight as a continuous variable or as the outcome variable, analyses that did not control or stratify by objective BMI or weight status (to minimise the potential confounding effect of objective weight). Studies published in languages other than English were excluded because translation was not feasible. We placed no restriction on country of origin or further restrictions on participant characteristics (e.g., gender, age group) in order to maximise the number of included studies, and because we planned to conduct subgroup analyses to explore differences across sample, participant, and methodological characteristics. See Appendix A (Supplemental Material) for further information on search strategy and eligibility.

\subsection{Information sources and search strategy}

Electronic searches of PubMed, PsycInfo, and Cumulative Index to Nursing and Allied Health Literature (CINAHL) databases were performed in June 2016 using search terms devised to identify articles related to perceived weight and outcome variables (Table S1). Database searches also targeted weight and eating-related outcomes (e.g., weight loss attempts, strategies, behaviours, disordered eating, and weight loss), which were included in a separate review (Haynes, Kersbergen, Sutin, Daly, \& Robinson 2018). In addition, we manually searched the reference lists of eligible articles for relevant articles and each author was responsible for suggesting additional articles. Supplementary database searches were also conducted in July 2017 (see Appendix A, Supplemental Material), and articles citing the eligible articles were identified using Google Scholar forward citation tracking in September 2017 to ensure coverage of recently published articles.

\subsection{Study selection}

Two researchers independently performed title and abstract screening of electronic search results for eligibility, and discrepancies were resolved by discussion ( $97.5 \%$ agreement, $\kappa=.95$ ['high']). The same reviewers subsequently performed independent full text screening of those articles (87.8\% agreement, $\kappa=.76$ ['substantial']). Discrepancies in screening decisions were resolved by discussion, and adjudicated by a third author when a decision could not be reached.

\subsection{Data extraction}

One of three reviewers extracted data from each eligible study, and the data extracted by each reviewer was cross-checked by another. Information about: (a) publication features (title, authors, year of publication, journal), (b) study methods (design, country of origin, measurement of perceived and objective weight status and outcomes, analysis features), (c) sample characteristics (sample size, and distribution of age, gender, and weight status), and (d) effect size (association between perceived weight status and depression or suicidality) were extracted for each study. If a study reported effects in different independent subsamples (e.g., stratified by gender), those effect sizes and information on design and analysis features were extracted separately. We only extracted effect sizes from analyses in which objective weight status category or BMI was included as a covariate or was used to stratify analyses, and where multiple statistical analyses of the same relationship were reported in one study, we extracted effect sizes from 
the most appropriately adjusted model (i.e., adjusted for variables known to be associated with weight perception such as gender, socioeconomic status). Individual meta-analyses only included effect sizes from independent samples (i.e., did not include multiple effect sizes from overlapping samples within or across studies, see Appendix B in Supplemental Materials for further information on data extraction).

Data were also extracted from eligible studies for exploratory analyses of the association between objective overweight and mental health outcomes, before and after controlling for perceived weight. Studies that were eligible for inclusion in this analysis were those which provided (a) an estimate of the association between objective weight status (enabling a comparison of overweight or obesity with a reference category of 'normal weight') and either depression or suicidality, without controlling for perceived weight and (b) the same estimate, controlling for perceived weight. Importantly, effects were only eligible if the analysis of (a) and (b) were identical (i.e., identical covariates, independent and dependent variable, subsample) except for the inclusion of perceived weight as a covariate in (b).

\subsection{Quality assessment}

We assessed the methodological quality of studies included in the review against a set of criteria (Table 1) adapted from established quality checklists for cross-sectional and longitudinal observational studies (Joanna Briggs Institute, 2014; Tooth, Ware, Bain, Purdie, \& Dobson, 2005). Two authors piloted the assessment tool by independently scoring 20 studies, with acceptable to high agreement for each criterion $(\kappa=0.69-1.00)$. The methodological quality of the remaining studies was then scored by one of those two authors. For each item, each study was scored as either meeting or not meeting the criterion, or as 'not applicable'. The number of positively scored items was divided by the total number of applicable criteria to construct a total quality score for each study. A study was judged as being of 'high quality' if it was assigned a quality score $\geq 70 \%$.

\subsection{Statistical analysis}

We pooled odds ratios (ORs) reflecting the odds of an outcome in individuals who perceived themselves as overweight relative to those who did not (i.e., perceived normal or healthy weight, or perceived normal and perceived underweight combined) for depressive symptoms and suicidality separately. See Appendix B in supplemental materials for additional information on effect size coding and conversion of effect sizes for continuous outcomes to ORs. Meta-analyses were conducted using the 'meta' package in Stata (Sterne, Bradburn, \& Egger, 2008), using the generic inverse variance method which allowed pooling of effect sizes adjusted for potential confounders (e.g., objective BMI, gender, age), rather than raw count data (e.g., \% of each weight perception group with outcome). Heterogeneity was assessed by calculating $I^{2}$ statistic $\left(I^{2}=\right.$ Cochran's Q - df $/ \mathrm{Q},<25 \%=$ low, $50 \%=$ moderate, $75 \%=$ high) (J. P. T. Higgins, Thompson, Deeks, \& Altman, 2003). As heterogeneity was moderate to high in a majority of the analyses, we conducted DerSimonian-Laird random effects meta-analyses. To examine signs of publication bias, we constructed funnel plots around fixed estimates, examined Egger's test and used trim and fill methods for each outcome (Duval \& Tweedie, 2000; Peters, Sutton, Jones, Abrams, \& Rushton, 2007; Sterne \& Harbord, 2004).

To further examine potential sources of heterogeneity and to provide effect size estimates for readers interested in specific populations, a series of subgroup analyses were conducted to estimate the pooled effect size within groups separated by gender ${ }^{1}$, age group (children/adolescents,

\footnotetext{
${ }^{1}$ Insufficient information was provided in published articles to determine whether participants were asked to report their assigned sex at birth or report their gender identity. We therefore use the term 'gender' in this review but note
}

adults), objective weight status (normal weight, overweight/obesity), sample origin (North America, Europe, Asia, other), and study design (cross-sectional, longitudinal). We also pooled estimates of the association between perceived overweight and mental health in the following outcome categories: clinically-significant depression (diagnosis or 'elevated depression symptoms' according to clinical criteria); sub-clinical depressive symptoms (severity or frequency of depressive symptoms or depressed mood); suicidal ideation; and suicide attempts. In addition, we conducted three sets of sensitivity analyses to examine pooled effect sizes separately for observations meeting versus not meeting the following criteria: (a) high quality (quality score $\geq 70 \%$ ) study; (b) analysis controls for BMI as a continuous variable; and (c) (for depression): outcome measured using a validated multi-item measure of depression (e.g., CES-D, BDI, instead of a single-item measure of depressed mood such as "in the past year, have you often felt depressed?" yes $/ \mathrm{no})^{2}$, (for suicidality): analysis controls for depressive symptoms. We also conducted meta-regression to test whether study-level characteristics distinguishing subgroups and sensitivity criteria (e.g., gender, study quality) predicted the strength of the association between perceived overweight and depression or suicidality.

To examine whether the association between objective overweight and mental health is partially attributable to perceived overweight, we also conducted an exploratory analysis of the association between weight status and depressive symptoms and suicidality ${ }^{3}$; first pooling effects where perceived weight was not statistically controlled for, and then pooling effects from otherwise identical models that controlled for perceived weight. Datasets and analysis scripts are available on Open Science Framework (https://osf.io/smbf7/).

\section{Results}

\subsection{Study selection}

Electronic database searches identified 10,398 unique records, an additional 41 articles were suggested by authors, or were identified in the reference lists of eligible articles or in supplementary searches. Full text review of 381 articles was conducted, which yielded 32 studies that were eligible for inclusion in the present review (listed in Appendix F, Supplemental Materials; Armstrong et al., 2014; ter Bogt et al., 2006; Brown and Blanton, 2002; Byeon, 2013; Byeon, 2015; Daly et al., 2017; Eaton et al., 2005; Frisco et al., 2010; Gaskin et al., 2013; Jansen et al., 2008; Kim, 2011; Kim et al., 2009; Kim, Kim, Cho, \& Cho, 2008; Kinoshita et al., 2012; Lee, 2017; Lee, Seo, Shim, \& Lee, 2015; Lenhart et al., 2011; Lim \& Kim, 2017; Lo et al., 2009; Lo et al., 2011; Roberts \& Duong, 2013; Schiefelbein et al., 2012; Seo \& Lee, 2013; Shin et al., 2015; Swahn et al., 2009; Thurston et al., 2017; Ting et al., 2012; Xie et al., 2006; Yuan, 2007, 2012; Zeller et al., 2013; Zhao et al., 2012). From those studies, 110 eligible effect sizes were extracted or calculated (Figure 1).

\subsection{Study and sample characteristics}

Characteristics of the 32 included studies and the observations from each $(k=110)$ that were eligible for analysis are presented in Table S2a. All observations were from cross-sectional analyses except for 7 that were longitudinal estimates for depression (from 3 separate studies). Length of follow-up in longitudinal studies ranged from 1 to 12

\section{(footnote continued)}

that this classification may be inaccurate for a very small proportion of participants across studies.

${ }^{2}$ Single-item self-report screening measures of depressive symptoms have low diagnostic accuracy relative to validated multi-item instruments and were therefore considered a marker of lower measurement quality in the sensitivity analysis (Donker, van Straten, Marks, \& Cuijpers, 2010; Rhew et al., 2010).

${ }^{3}$ No studies reported an analysis of the association between BMI as a continuous variable and mental health, and then subsequently controlled for weight perception. 
Table 1

Assessment criteria: methodological quality of included studies.

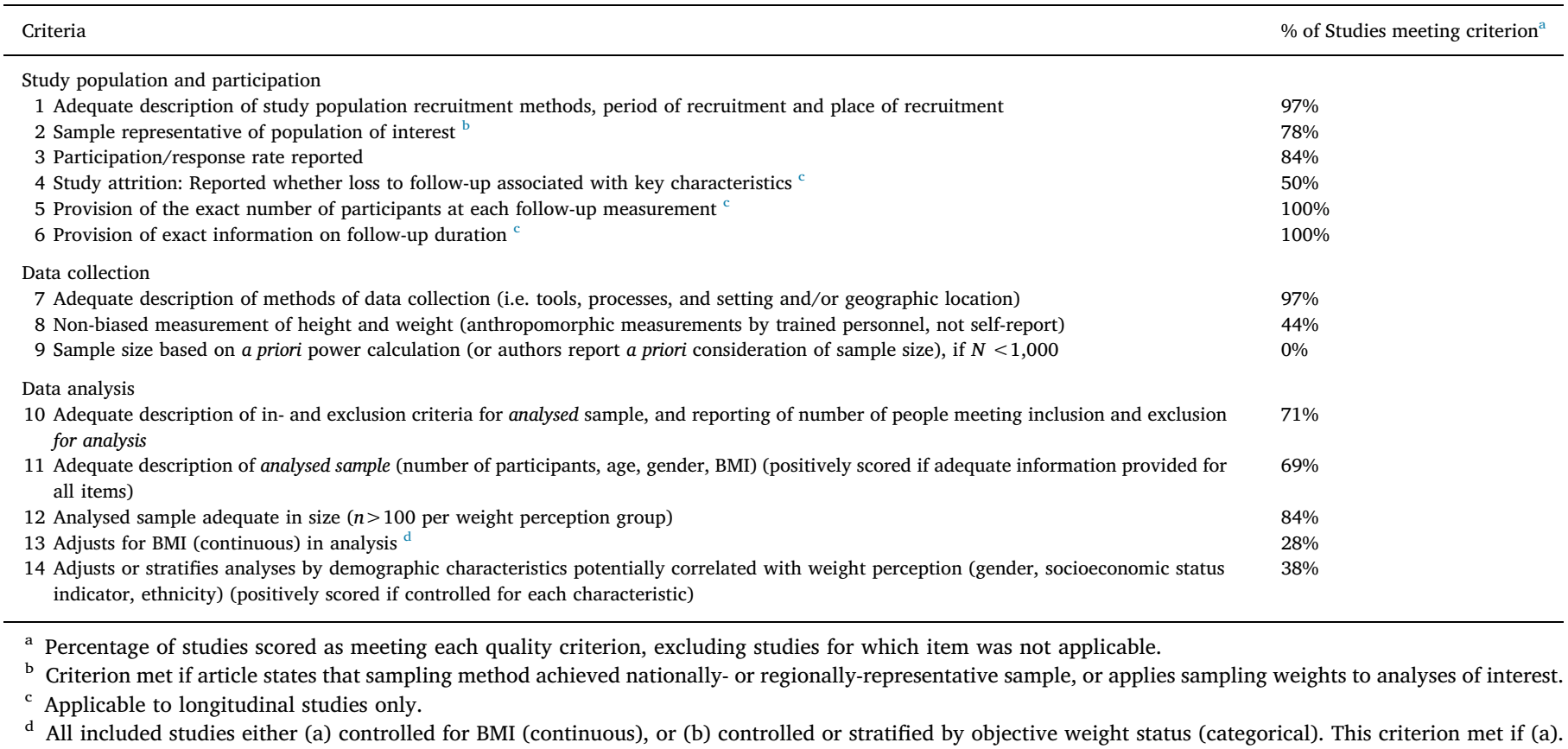

years. Most studies were conducted in Asia (Korea, China, Hong Kong, or Japan: 15 studies) or the United States (15), and 2 were conducted in the Netherlands. Study sample sizes ranged from 106 to 109,373. The majority (58) of observations extracted were from males and females combined, and a large number were from participants of different objective weight status (50). The remainder of observations were from only males (22), females (30), participants with overweight or obesity (36), or with normal weight (or not overweight, 24). The majority of observations were from samples of participants aged 7-20 years (child/ adolescent samples) (92).

\subsection{Measurement characteristics}

Perceived weight was measured in all included studies by asking participants to describe their current weight on a rating scale. In the majority of studies (75\%, Table S2b), participants responded by selecting one of the following options: 'very underweight', 'slightly underweight', 'about right' (or variants 'acceptable', 'normal', 'average'), 'slightly overweight' (or 'somewhat overweight'), 'very overweight' (or 'obese'). The responses 'slightly' or 'very overweight' were categorised as 'perceived overweight' in most studies, and outcomes were compared between participants with 'perceived overweight' and a reference category of 'perceived normal weight' in a majority of studies (73\%). The remainder of studies compared 'perceived overweight' with 'perceived not overweight'. Objective weight status was categorised from BMI based on age and gender-specific percentiles for child and some adolescent samples, and region-specific criteria for samples outside USA (Table S2a).

The outcome measure was depression or depressive symptoms in 23 studies (contributing 58 observations), and were mostly assessed with a single self-report item or validated questionnaire (Table S2a). The outcome measure in 8 studies (contributing 22 observations) was a diagnosis of depression using a standardised clinical interview or 'clinically significant' levels of depressive symptoms (self-reported symptoms dichotomised according to clinical criteria). The outcome measure in the remaining observations (36) was severity or frequency of depressive symptoms assessed by self-report (with no reference to clinical diagnostic criteria). Suicidality was the outcome measure in 10 studies, and of the 52 eligible observations from these studies, 21 were of suicidal ideation, 24 were of suicide attempts, and 6 observations were of a combined measure encompassing both ideation and attempts. Suicidality was assessed in all studies by asking participants to report whether they had seriously considered, made plans to, or attempted to commit suicide either in the past year or ever (see Table S2a).

\subsection{Methodological quality}

The majority of studies eligible for review (53.1\%) were judged to be of high methodological quality, and the average quality score was $68 \%$ (Table S3). The quality criteria that were most commonly met by eligible studies were the provision of an adequate description of recruitment (97\%) and data collection methods (97\%); and for longitudinal studies, a description of the follow-up duration and reporting of the number of participants at each follow-up measurement (each $100 \%$, Table 1). Lack of evidence concerning appropriateness of sample size (e.g., power calculation) in studies with $N<1,000$ (no applicable studies met this criterion) and lack of demonstration that loss to follow up was not associated with key characteristics in longitudinal studies (50\% of applicable studies met this criterion) were the most prevalent potential sources of bias. Thirty eight percent of studies did not adjust for demographic variables known to be associated with weight perception (e.g., socioeconomic status, Paeratakul, White, Williamson, Ryan, \& Bray, 2002), and $28 \%$ did not adjust for BMI as a continuous variable in analyses.

\subsection{Association between perceived overweight and depressive symptoms}

Fig. 2 presents a forest plot of the analysis of the association between perceived overweight and depressive symptoms. Overall, participants who perceived themselves as overweight had higher odds of depressive symptoms, OR: 1.42 , 95\% CI: $1.31,1.54, p<.0001$, although there was evidence of high heterogeneity, $I^{2}=85 \%, Q(32)=$ 212.56, $p<.0001$ ( $k=33, n>128,585$ with 1 observation for which $n$ was not extracted). Visual inspection of the funnel plot (Fig. 3) of effect size (OR) against standard error indicated minor asymmetry, however Egger's test was not statistically significant, bias $=1.18, \mathrm{SE}=0.62$, 


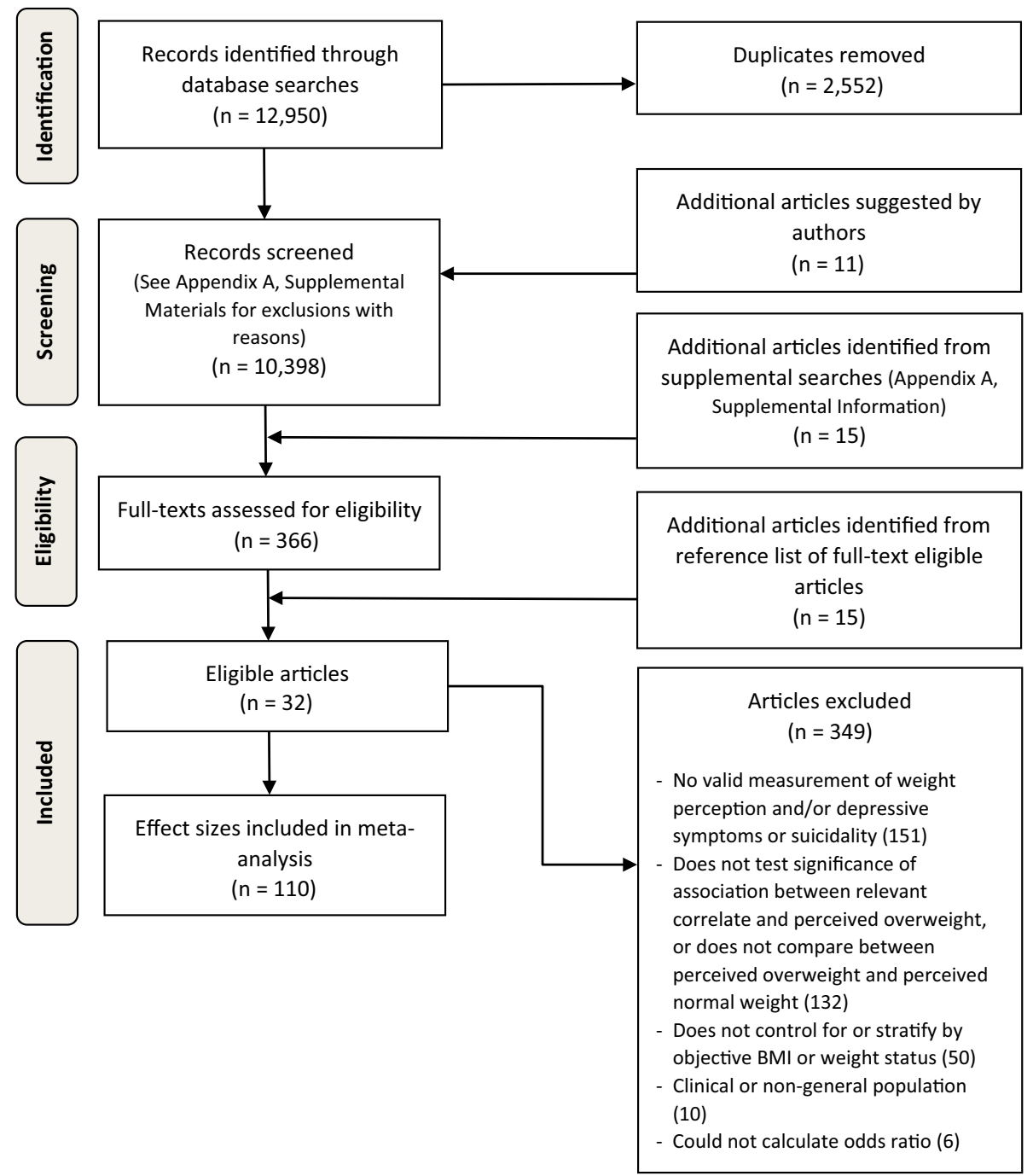

Fig. 1. PRISMA flow diagram of study selection, inclusion, and exclusion.

$95 \% \mathrm{CI}=-0.08,2.45, p=.066$. The trim-and-fill method identified 10 hypothetical unpublished observations, and the effect estimate adjusted to include these data was smaller but consistent with the main effect estimate, OR: $1.30,95 \%$ CI: $1.20,1.41, p<.0001$.

\subsubsection{Subgroup and sensitivity analyses}

Table 2 presents the results of meta-analyses of the association between perceived overweight and depressive symptoms within subgroups divided by sample and study characteristics, and sensitivity analyses examining effects within groups split by study quality, whether or not analyses controlled for continuous BMI, and the use of validated depression measures. Between-study heterogeneity was high $\left(I^{2}\right.$ $>75 \%$ ) in all subgroup and sensitivity analyses, except for adult samples and longitudinal studies (low), and in the analysis of subclinical depressive symptoms (moderate). Consistent with results of the primary meta-analysis, perceived overweight (relative to perceived normal or non-overweight) was associated with significantly higher odds of depressive symptoms in all subgroup and sensitivity analyses, except for in samples of individuals with overweight or obesity, where the association was in the same direction but was not statistically significant. A series of meta-regressions indicated that none of the extracted participant or study characteristics moderated the strength of the relationship between perceived overweight and depressive symptoms (see Table S4, Supplemental Material for full meta-regression results).

\subsubsection{Weight status and depressive symptoms}

Objective overweight status (relative to normal weight) was associated with greater odds of depressive symptoms, OR: 1.31 , $95 \% \mathrm{CI}$ : $1.06,1.60, p=.011$, although there was evidence of high heterogeneity, $I^{2}=91 \%, Q(12)=139.06, p=.108(k=13, n>39,412$ with 2 observations for which $n$ was not extracted). After adding weight perception to the predictive model, overweight was no longer associated with depressive symptoms, OR: 1.02 , 95\% CI: 0.86, $1.22 p=$ .794, and again there was evidence of high heterogeneity, $I^{2}=80 \%, Q$ $(12)=60.02, p=.061$. See Appendix E (Supplemental Material) for forest plots.

\subsection{Association between perceived overweight and suicidality}

A forest plot of effect sizes from observations of the association between perceived overweight and suicidality is shown in Fig. 4. Overall, participants who perceived themselves as overweight were at higher risk of suicidality, OR: $1.33,95 \%$ CI: $1.21,1.45, p<.0001(k=$ $20, n=133,576$ ), although there was moderate between-study heterogeneity, $I^{2}=68 \%, Q(19)=62.94, p<.0001$. Visual inspection of the funnel plot (Fig. 5) of OR against standard error indicated some asymmetry but Egger's test was not significant, bias $=1.11, \mathrm{SE}=0.73$, $95 \% \mathrm{CI}=-0.43,2.65, p=.148$. For completeness, we used the trimand-fill method to adjust the effect estimate for missing studies. This method identified 5 hypothetical unpublished observations, and the 


Observation
Armstrong (2015)
Byeon (2013)
Daly (2017)
Gaskin (2013) a
Gaskin (2013) b
Kim (2008) a
Lee (2015)
Lee (2017)
Lenhart (2011) d
Lim (2017) a
Lim (2017) b
Lo (2009)
Lo (2011) a
Lo (2011) c
Roberts (2013) a
Roberts (2013) d
Schiefelbein (2012) a
Schiefelbein (2012) b
Schiefelbein (2012) c
Schiefelbein (2012) d
Thurston (2017) f
Thurston (2017) g
Thurston (2017) h
Thurston (2017) i
Thurston (2017) j
Ting (2012)
Xie (2006) a
Xie (2006) b
Yuan (2007) a
Yuan (2007) b
Zhao (2012) a
Zhao (2012) b
ter Bogt (2006)
Combined
$\quad$ I
$\quad$.1

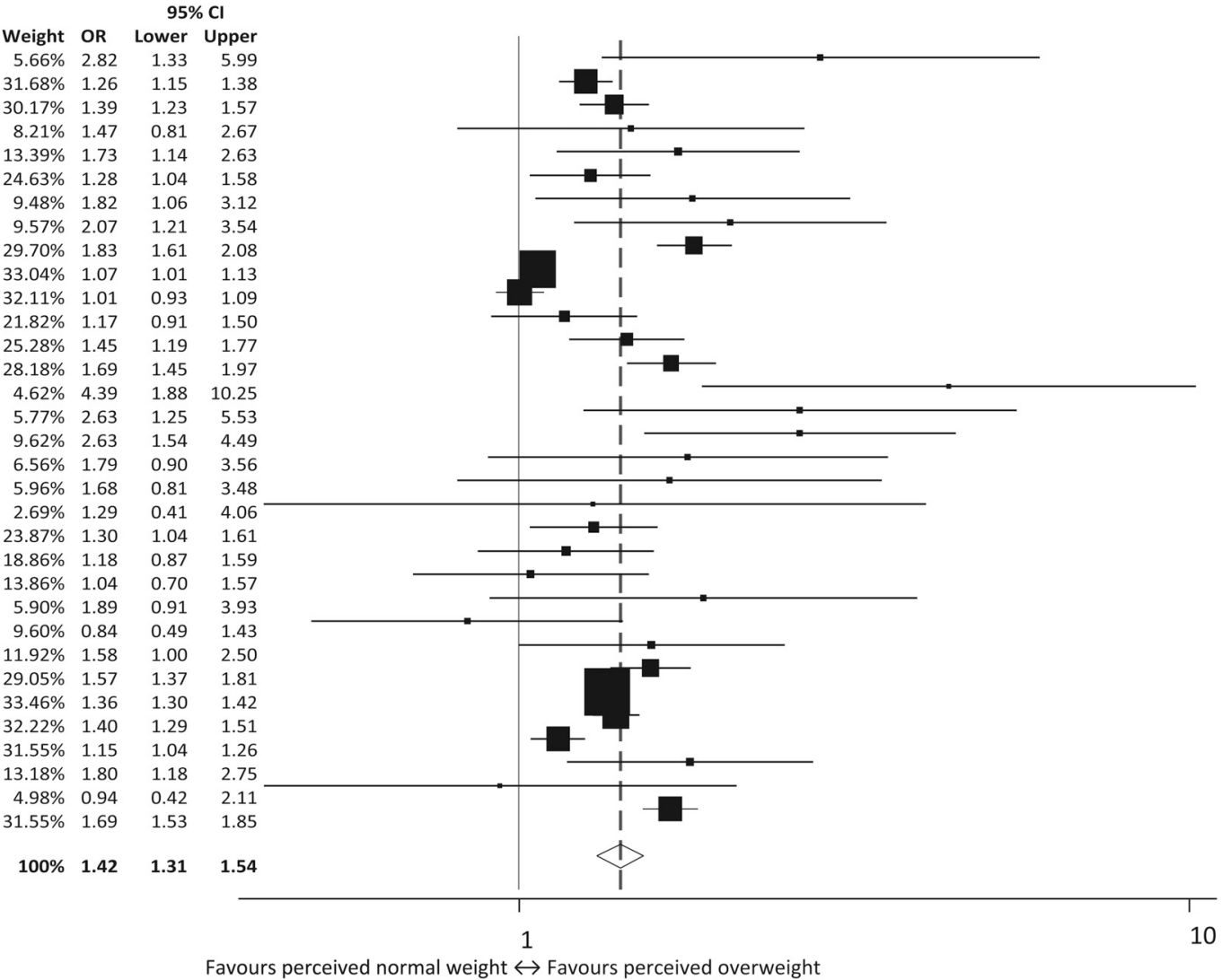

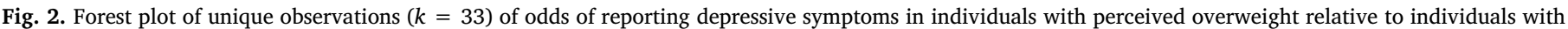

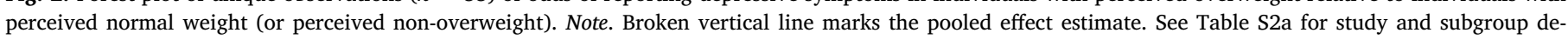
scriptions.

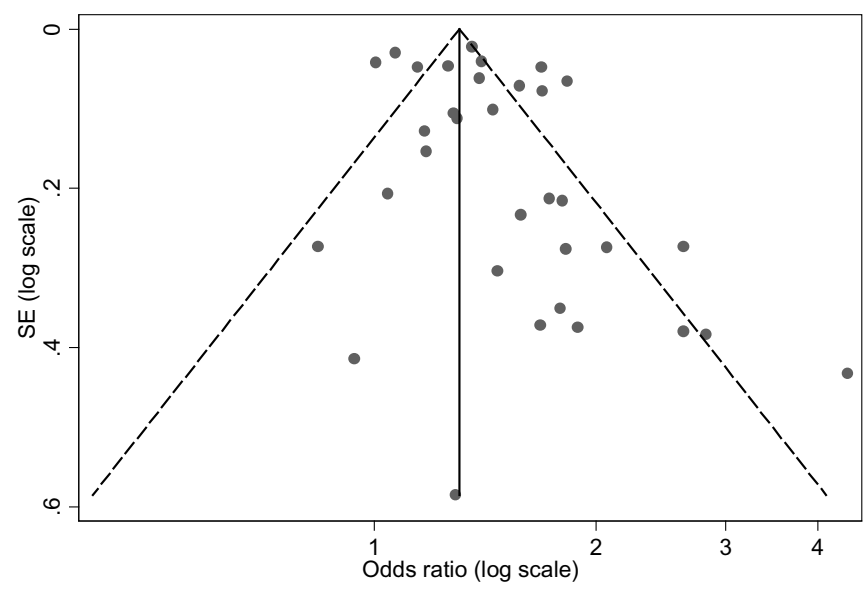

Fig. 3. Funnel plot of odds ratio by standard error: association between perceived overweight and depressive symptoms. Note. Each mark displays an observation $(k=33)$. Vertical line marks the pooled effect estimate, broken lines mark $95 \%$ confidence intervals around the pooled estimate.

effect estimate recalculated with these hypothetical data included resulted in an effect that was consistent with the main estimate, OR: 1.25, 95\% CI: $1.13,1.37, p<.0001$.

\subsubsection{Subgroup and sensitivity analyses}

Table 3 presents the results of meta-analyses of the association between perceived overweight and suicidality within subgroups divided by participant and study characteristics, and sensitivity analyses examining effects within groups split by study quality, and whether or not analyses controlled for continuous BMI or depressive symptoms. There was substantial between-study heterogeneity in subgroups consisting of female participants, those with overweight/obesity, and in analyses that controlled for depressive symptoms $\left(I^{2}>75 \%\right)$, but low to moderate heterogeneity in the remaining subgroups and sensitivity analyses. The results of all subgroup and sensitivity analyses were consistent with the main analysis (i.e., perceived overweight was associated with greater odds of suicidality), but effects were in the same direction but not statistically significant in male or female subgroups, observations that controlled for continuous BMI, or within high quality studies. Meta-regression analyses indicated that perceived overweight was more strongly associated with suicidality in North American than Asian samples, and in studies where the reference group was 'perceived normal weight' (rather than 'non-perceived overweight'), although subgroup analyses based on these characteristics were all significant. No other extracted participant or study characteristics moderated the strength of the relationship between perceived overweight and suicidality (see Table S5, Supplemental Material for full meta-regression results).

\subsubsection{Weight status and suicidality}

Overweight was associated with greater odds of suicidality relative to normal weight, OR: $1.23,95 \%$ CI: $1.11,1.36, p<.0001$, with moderate heterogeneity, $I^{2}=55 \%, \mathrm{Q}(7)=15.72, p=.03(k=8, n>$ 72,047 with 2 observations for which $n$ was not extracted). Higher weight status was no longer associated with suicidality when estimates from predictive models controlling for perceived overweight were pooled, OR: $1.00,95 \%$ CI: $0.94,1.06 p=.976$, with no heterogeneity, $I^{2}=0 \%, \mathrm{Q}(7)=6.23, p=.51$. See Appendix E (Supplemental Material) for forest plots. 
Table 2

Pooled estimates from subgroup and sensitivity analyses: association between perceived overweight and depressive symptoms

\begin{tabular}{|c|c|c|c|c|c|c|}
\hline & OR & $95 \% \mathrm{CI}$ & $I^{2}$ & $Q$ & $k$ & $n$ \\
\hline \multicolumn{7}{|l|}{ Subgroup analyses } \\
\hline Male & $1.38^{* *}$ & $1.19,1.60$ & $86 \%$ & $70.86^{\dagger}$ & 11 & $>43,540^{1}$ \\
\hline Female & $1.51^{* *}$ & $1.32,1.72$ & $85 \%$ & $94.86^{\dagger}$ & 15 & $>80,843^{1}$ \\
\hline Children/adolescents & $1.42^{* *}$ & $1.30,1.55$ & $87 \%$ & $207.99^{\dagger}$ & 28 & $>104,238^{1}$ \\
\hline Adults & $1.40^{* * *}$ & $1.27,1.54$ & $0 \%$ & 2.65 & 5 & 24,347 \\
\hline Normal weight & $1.32^{* *}$ & $1.19,1.47$ & $85 \%$ & 87.82 & 14 & $>29,903^{3}$ \\
\hline Overweight/obesity & 1.18 & $0.94,1.49$ & $76 \%$ & $33.46^{\dagger}$ & 9 & $>2,869^{3}$ \\
\hline North America & $1.48^{* *}$ & $1.31,1.68$ & $73 \%$ & $62.08^{\dagger}$ & 18 & 49,008 \\
\hline Asia & $1.34^{* *}$ & $1.21,1.49$ & $88 \%$ & $106.24^{\dagger}$ & 14 & 79,577 \\
\hline Europe & $1.69^{* *}$ & $1.53,1.85$ & $n / a$ & $n / a$ & 1 & 1 \\
\hline Cross-sectional & $1.51^{* *}$ & $1.38,1.66$ & $88 \%$ & $215.39^{\dagger}$ & 26 & $>127,604^{1}$ \\
\hline Longitudinal & $1.35^{* *}$ & $1.16,1.58$ & $25 \%$ & 4.00 & 4 & 11,689 \\
\hline $\begin{array}{l}\text { Compares perceived } \\
\text { 'normal weight' }\end{array}$ & $1.39^{* *}$ & $1.26,1.53$ & $83 \%$ & $160.28^{\dagger}$ & 28 & 117,833 \\
\hline $\begin{array}{l}\text { Compares perceived } \\
\text { 'not-overweight' }\end{array}$ & $1.55^{* *}$ & $1.34,1.78$ & $84 \%$ & $24.69^{\dagger}$ & 5 & 10,752 \\
\hline $\begin{array}{l}\text { Sub-clinical } \\
\text { depressive } \\
\text { symptoms }\end{array}$ & $1.39^{* *}$ & $1.29,1.49$ & $71 \%$ & $58.83^{\dagger}$ & 18 & $>58,020^{1}$ \\
\hline $\begin{array}{l}\text { Clinically-significant } \\
\text { depression }\end{array}$ & $1.56^{* *}$ & $1.34,1.81$ & $86 \%$ & $117.58^{\dagger}$ & 17 & 74,463 \\
\hline
\end{tabular}

\begin{tabular}{|c|c|c|c|c|c|c|}
\hline Sensitivity analyses & & & & & & \\
\hline Low study quality & $1.70^{* * *}$ & $1.42,2.03$ & $79 \%$ & $52.17^{\dagger}$ & 12 & $>38,073^{1}$ \\
\hline High study quality & $1.35^{* * *}$ & $1.24,1.47$ & $83 \%$ & $131.03^{\dagger}$ & 23 & 94,328 \\
\hline $\begin{array}{l}\text { Does not control } \\
\text { continuous BMI }\end{array}$ & $1.47^{* * *}$ & $1.28,1.69$ & $91 \%$ & 163.46 & 16 & $>69,568^{1}$ \\
\hline $\begin{array}{l}\text { Controls for } \\
\text { continuous BMI }\end{array}$ & $1.34^{* * *}$ & $1.20,1.50$ & $88 \%$ & $103.44^{\dagger}$ & 13 & 111,572 \\
\hline $\begin{array}{c}\text { Non-validated } \\
\text { depression } \\
\text { measure }\end{array}$ & $1.43^{* *}$ & $1.25,1.34$ & $88 \%$ & 119.65 & 16 & 79,294 \\
\hline $\begin{array}{l}\text { Validated depression } \\
\text { measure }\end{array}$ & $1.42^{* * *}$ & $1.30,1.54$ & $73 \%$ & $58.88^{\dagger}$ & 17 & $49,291^{1}$ \\
\hline
\end{tabular}

$k$ number of observations.

** Pooled effect $p<.0001$.

$\uparrow$ Significant $Q(p<.1$ with $k-1 \mathrm{df})$. Numbered superscript in column $n$ indicates number of observations $k$ for which $n$ could not be extracted.

\section{Discussion}

The present review revealed that self-identification as 'overweight' is associated with significantly higher odds of depressive symptoms and suicidality, in comparison to not identifying oneself as overweight. Notably, our analyses provide some indication that perceived overweight is a prospective risk factor for future declines in mental health (depression). In addition, we found that perceived overweight was associated with poorer mental health represented by clinically-significant levels of depression and attempted suicide, as well as subclinical levels of depressive symptoms and suicidal ideation. Analyses also revealed that the demonstrated association between objective overweight status and poor mental health may be attributable to whether or not a person identifies that they are categorised as overweight.

Restricting analyses to include only longitudinal studies controlling for depressive symptoms at baseline established a prospective link between perceived overweight and future onset of depressive symptoms. One study found an association between perceived overweight at baseline and risk of suicide attempts at 1 year later in adolescent girls but not boys (Seo \& Lee, 2013), however we did not include these estimates in a longitudinal subgroup analysis as baseline levels of suicidality were not controlled. The conclusion that perceived overweight was associated with suicidality was primarily based on cross-sectional evidence, which therefore precludes conclusions about the causal direction of this relationship. While our longitudinal analyses controlling for baseline levels of depression outcomes enabled evaluation of the temporal pathway between perceived overweight and later mental health, we did not extract evidence for the relationship in the opposite direction. It is possible that the negative cognitive biases that are a risk and maintaining factor of depression predispose an individual to subsequently perceive themselves as overweight and therefore confound cross-sectional associations between weight perception and depression (Everaert, Podina, \& Koster, 2017). Further, the present review cannot rule out the existence of additional factors that may predispose individuals to both perceived overweight and poor mental health such as neuroticism (O'Connor \& Nock, 2014; Sutin \& Terracciano, 2016) or low self-esteem (Miller \& Downey, 1999). To rule out this possibility requires controlled experimental studies exploring the effect of manipulating weight status perceptions on mental health.

Despite the results of some individual studies suggesting an association between perceived overweight and depressive symptoms for females but not males (Yuan, 2007; Zhao et al., 2012) and studies showing stronger associations between overweight and poor self-esteem for women than men (Miller \& Downey, 1999), gender did not moderate the association between perceived overweight and poor mental health indicated by either depressive symptoms or suicidality. Although societal standards tend to value physical attractiveness to a greater extent in women than in men (Fredrickson \& Roberts, 1997; McKinley, 1998), a recent report indicates that weight stigma experienced by men is comparable to estimates from mixed-gender samples (Himmelstein, Puhl, \& Quinn, 2018). The consistent effects observed across genders in the present review could therefore be due to both men and women being conscious of the societal devaluation of individuals with overweight and obesity.

We pooled results across a range of geographic regions which will have differed in prevalence of overweight and obesity, depression, and suicidality (World Health Organization, 2016, 2017), which may have contributed to the heterogeneity in overall effect estimates. However, we found that the associations between perceived overweight and mental health were observed across countries: while the relationship for suicidality was stronger in studies conducted in North America than in Asia, perceived overweight was significantly associated with poorer mental health across all subgroups. Although the studies included in the review originated from a limited range of countries, the consistent pattern of results could reflect the ubiquity of weight stigma and the thin body weight ideal (Brewis, SturtzSreetharan, \& Wutich, 2018; Crystal, Watanabe, \& Chen, 2000; Klaczynski, 2008; Puhl et al., 2015; Swami et al., 2010). We identified a comparable number of studies from countries where the primary language is English (e.g., USA) versus another language (e.g., the Netherlands, China, Korea), however the exclusion of studies not published in English introduces a potential source of bias. Historically, lower levels of weight stigma have been documented in developing countries than high income countries, but weight stigma is now becoming a global challenge which some have attributed to growing rates of obesity (Brewis et al., 2018; Hackman, Maupin, \& Brewis, 2016). Exploring the psychological correlates of body weight perceptions in more diverse cross-cultural samples, including in middle-income and developing nations in which weight stigma is becoming more widespread is an important direction for future research (Brewis et al., 2011). Alternatively, examining the consequences of perceived overweight in societies that do not widely stigmatise overweight and obesity would be informative about the role of weight stigma in these relationships. While it was common for included studies to control for race or ethnicity in analyses, it was not possible to conduct subgroup analyses in the present review as too few studies provided estimates stratified by race or ethnicity. There is some evidence to suggest that perceived overweight is associated with poorer mental health in white adolescents but not those of other ethnicities (Eaton et al., 2005; Thurston et al., 2017), highlighting a need for further research on the effects of perceived weight by race and ethnicity. 


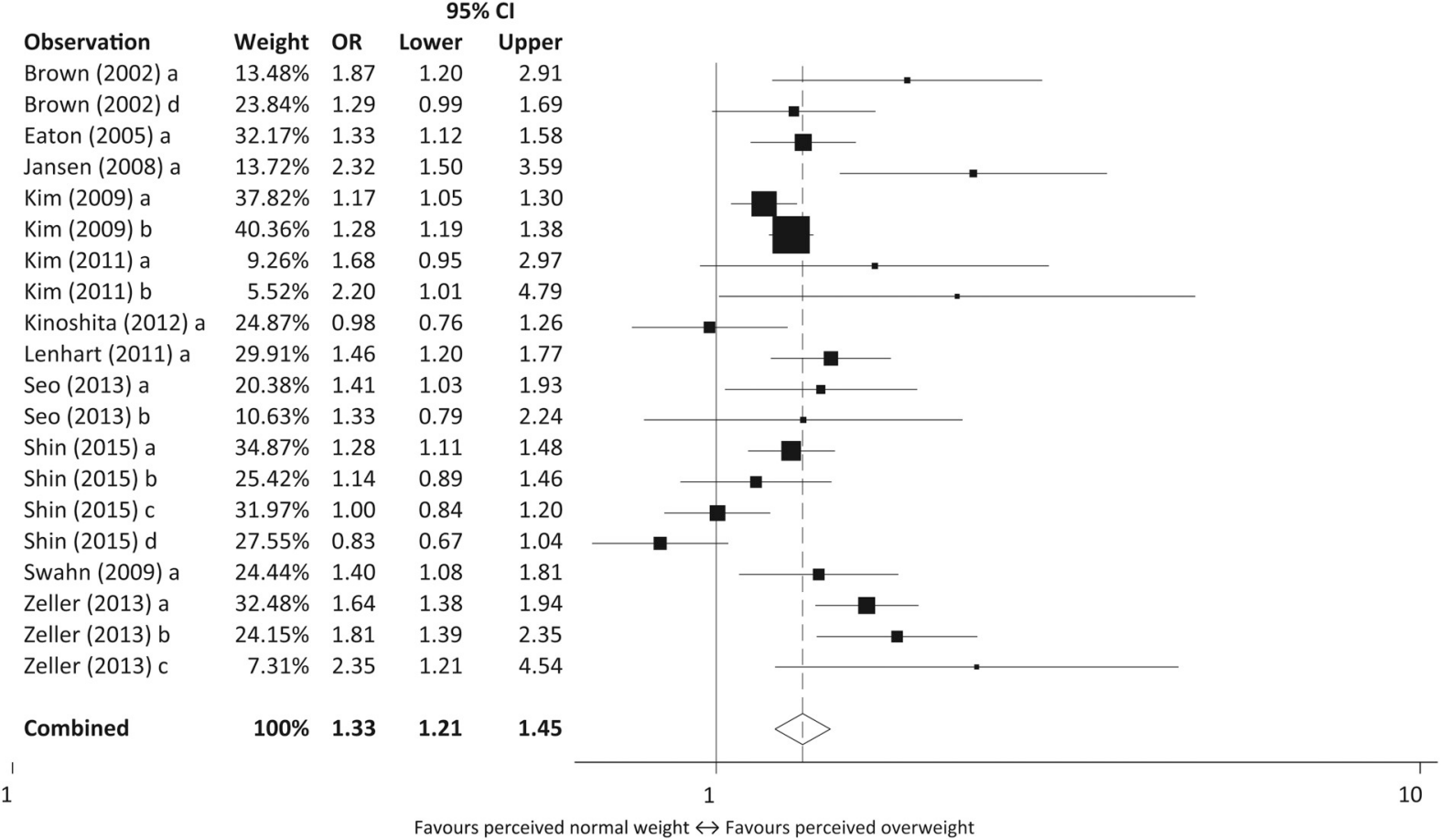

Fig. 4. Forest plot of unique observations $(k=20)$ of odds of suicidality in individuals with perceived overweight relative to individuals with perceived normal weight (or perceived non-overweight). Note. Broken vertical line marks the pooled effect estimate. See Table S2a for study and subgroup descriptions.

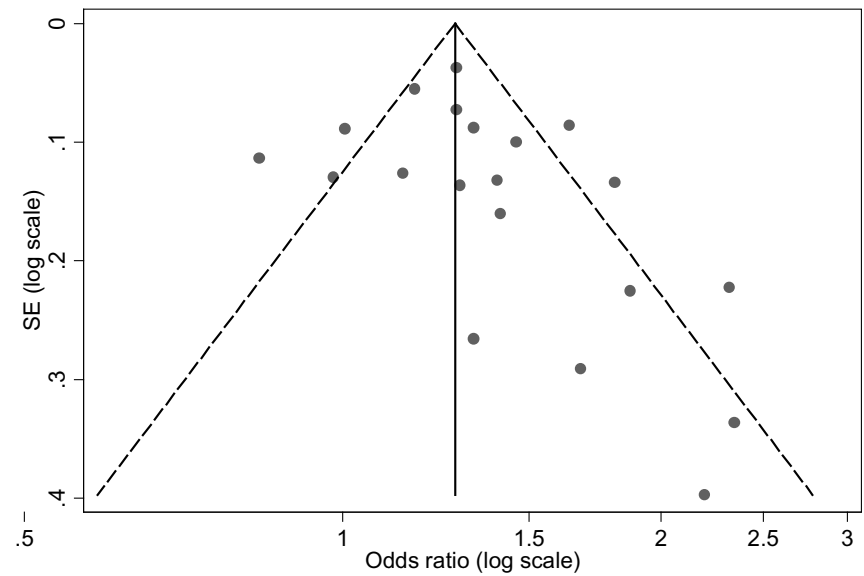

Fig. 5. Funnel plot of odds ratio by standard error: association perceived overweight and suicidality. Note. Each mark displays an observation $(k=20)$ as a function of effect size and standard error. Vertical line marks the pooled effect estimate, broken lines mark 95\% confidence intervals around the pooled estimate.

Despite changes in weight, body dissatisfaction, weight control practices, and psychological health between adolescence and midlife (Jones \& Meredith, 2000; Keel, Baxter, Heatherton, \& Joiner Jr, 2007), age group did not moderate the link between perceived overweight and either depressive symptoms or suicidality in the present review. These consistent findings could be attributable to the grouping of 'child and adolescent' samples for comparison with 'adult' samples. This analysis strategy was constrained by the effects reported in published articles, but further analysis of large longitudinal samples could examine developmental trajectories of the association between weight perception and mental health in order to determine at what age perceived overweight has the strongest impact on mental health.

The primary analyses pooled results across samples with varying participant and measurement characteristics (e.g., geographic regions,
Table 3

Pooled estimates from subgroup and sensitivity analyses: association between perceived overweight and suicidality

\begin{tabular}{lllllll}
\hline & OR & $95 \% \mathrm{CI}$ & $I^{2}$ & $Q$ & $k$ & $N$ \\
\hline Subgroup analyses & & & & & & \\
\hline Male & 1.13 & $0.96,1.31$ & $47 \%$ & $11.42^{\dagger}$ & 7 & $>38,206^{1}$ \\
Female & 1.17 & $0.95,1.44$ & $86 \%$ & $56.35^{\dagger}$ & 9 & $>48,048^{1}$ \\
Children/adolescents & $1.40^{* *}$ & $1.26,1.55$ & $67 \%$ & $33.24^{\dagger}$ & 12 & 100,502 \\
Adults & $1.21^{*}$ & $1.02,1.44$ & $69 \%$ & $22.24^{\dagger}$ & 8 & 33,074 \\
Normal weight & $1.33^{* *}$ & $1.14,1.54$ & $44 \%$ & 5.38 & 4 & 30,104 \\
Overweight/obesity & $1.41^{*}$ & $1.10,1.81$ & $85 \%$ & $43.91^{\dagger}$ & 7 & 20,958 \\
North America & $1.49^{* *}$ & $1.37,1.62$ & $1 \%$ & 9.48 & 10 & 41,013 \\
Asia & $1.14^{*}$ & $1.03,1.27$ & $67 \%$ & $24.53^{\dagger}$ & 9 & 89,375 \\
Europe & $2.32^{* *}$ & $1.50,3.59$ & $n / a$ & $n / a$ & 1 & 3,188 \\
Perceived 'normal & $1.21^{* *}$ & $1.10,1.34$ & $69 \%$ & $35.49^{\dagger}$ & 13 & 106,194 \\
$\quad$ weight' & & & & & & \\
Perceived 'not- & $1.56^{* *}$ & $1.41,1.73$ & $10 \%$ & 6.70 & 7 & 27,382 \\
$\quad$ overweight' & & & & & & \\
Suicidal ideation & $1.30^{* *}$ & $1.17,1.45$ & $74 \%$ & $57.50^{\dagger}$ & 16 & 114,670 \\
Suicide attempt & $1.27^{*}$ & $1.10,1.46$ & $23 \%$ & 15.54 & 13 & 30,017 \\
\hline
\end{tabular}

Sensitivity analyses

\begin{tabular}{lllllll}
\hline Low study quality & $1.42^{* *}$ & $1.28,1.58$ & $58 \%$ & $35.63^{\dagger}$ & 13 & 95,487 \\
High study quality & 1.17 & $0.99,1.38$ & $69 \%$ & $19.58^{\dagger}$ & 7 & 38,089 \\
$\begin{array}{l}\text { Does not control } \\
\quad \text { continuous BMI }\end{array}$ & $1.38^{* *}$ & $1.24,1.53$ & $72 \%$ & $57.69^{\dagger}$ & 17 & 104,984 \\
$\begin{array}{c}\text { Controls for continuous } \\
\quad \text { BMI }\end{array}$ & 1.16 & $0.99,1.36$ & $41 \%$ & 3.36 & 3 & 28,592 \\
$\begin{array}{c}\text { Does not control } \\
\quad \text { depression }\end{array}$ & $1.41^{* *}$ & $1.28,1.56$ & $0 \%$ & 4.16 & 7 & 29,538 \\
$\begin{array}{c}\text { Controls for depression } \\
\text { nel }\end{array}$ & $1.28^{* *}$ & $1.14,1.44$ & $78 \%$ & $54.07^{\dagger}$ & 13 & 104,038
\end{tabular}

$k$ number of observations.

$* \mathrm{p}<.05$

** $\mathrm{p}<.0001$

+ significant $Q(p<.1$ with $k-1 \mathrm{df})$. Numbered superscript in column $n$ indicates number of observations for which $n$ could not be extracted. No estimate for cross-sectional versus longitudinal, as all studies were classed as cross-sectional. 
age groups, outcome variables), however subgroup analyses shed little light on sources of the between-subject heterogeneity that was observed in the primary analyses and most of the subgroup analyses themselves were characterised by moderate to high heterogeneity. In one instance when depression studies were stratified into subgroups and examined in isolation (relation between perceived overweight and depression in studies with participants categorised as overweight only) the association between perceived overweight and depression remained in the expected direction (18\% increased risk) but was not statistically significant. Likewise, this was observed for a minority of the stratified suicidality estimates (e.g. male and females separately, high quality studies only). However, we did not find any statistical evidence in formal tests of sub-group moderation (meta-regression) that these study characteristics (e.g. objective weight status, gender, study quality) moderated the effect of perceived overweight on depression or suicidality. Thus, these few instances of statistically non-significant effects of perceived overweight when smaller numbers of studies were examined in isolation may in part reflect a lack of statistical power. Further research targeting these specific sub-groups of studies would now be valuable.

We extracted and combined adjusted effect sizes where available, rather than extracting raw frequency data which was often not reported in eligible studies. Differences in statistical adjustment for covariates between studies therefore presents a probable source of heterogeneity. Alternatively, the unexplained heterogeneity could be attributable to other aspects of the study samples or design that were either unreported in included studies or not uncovered in data extraction. Future work on the potential moderators and sources of heterogeneity in the relationship between perceived overweight and mental health would therefore be valuable. One possibility is that the intersection of multiple inequalities (e.g., multiplicative effects of ethnicity, gender, class) may more strongly moderate the relationship between perceived overweight and mental health than any one factor in isolation (Ciciurkaite \& Perry, 2018; Himmelstein, Puhl, \& Quinn, 2017). The robustness of the estimates derived from our primary analyses are supported by the results of meta-regression and trim-and-fill analyses. Specifically, none of the factors indicating more stringent study methodology (i.e., high study quality score, statistical control for continuous BMI or depressive symptoms [in suicidality analysis], or use of a validated multi-item outcome measure for depression) formally moderated the association between perceived overweight and mental health in meta-regression analyses. While the association between perceived overweight and suicidality was not statistically significant in high quality studies and those that controlled for continuous BMI, it was in a direction consistent with the results of the primary analyses (ORs $=1.16-1.17$ ). While there was some evidence of publication bias in the literature, adjusting for hypothetical missing studies yielded patterns of results consistent with the primary analyses.

Objective weight status did not formally moderate the strength of the relationship between perceived overweight and mental health problems in meta-regression analyses. The relationship between perceived overweight and depressive symptoms was statistically significant in analyses limited to individuals with normal weight and directional $(\mathrm{OR}=1.18)$ but not significant in analyses limited to individuals with overweight. However, we found that objective overweight status was associated with increased risk of experiencing depressive symptoms and suicidality (consistent with Heneghan et al., 2012; Pereira-Miranda et al., 2017; Quek et al., 2017; but see Atlantis \& Baker, 2008; Klinitzke, Steinig, Blüher, Kersting, \& Wagner, 2013; Perera et al., 2016; Zhang et al., 2013), but this relationship was no longer significant after controlling for perceived overweight. These results suggest that realising you are categorised as overweight rather than one's objective weight status is responsible for the adverse mental health outcomes that have been shown to be associated with overweight, and are consistent with the view that weight stigma is at the core of this psychological experience. Contemporary conceptualisations of stigma emphasise that stigma encompasses not only objective situational experiences (e.g., actual discrimination or reactions from others such as social rejection, exclusion, or overt indicators of negative evaluation), but also encompasses an individual's personal experience and awareness of the societal devaluation of their identity (Link \& Phelan, 2001; Major \& O'Brien, 2005). Individuals who merely perceive themselves as overweight may therefore fear negative evaluation and rejection from others, regardless of whether they are objectively categorised as overweight or whether they have previously experienced personally-directed denigration or discrimination based on their weight. This proposition is supported by recent evidence indicating that the tendency for perceived overweight to be associated with unhealthy eating behaviour is explained in part by concerns about being stigmatised based on weight among those who self-identify as overweight (Romano, Haynes, \& Robinson, 2018). This fear of social devaluation resulting from perceiving oneself as being part of a stigmatised group may threaten core psychological needs of belongingness and acceptance, and in turn damage mental health (Baumeister \& Leary, 1995; Williams, 2007; Wirth \& Williams, 2009).

It is also plausible that the poorer mental health outcomes that were found to be associated with perceived and actual overweight are attributable to higher levels of disordered eating and weight control behaviours. Perceived overweight may promote unhealthy weight control behaviours, such as excessive dietary restriction, laxative use, and vomiting (D. S. Kim et al., 2009; Lee et al., 2015). These practices can lead to weight gain and have been shown to predict the development of depressive symptoms (Neumark-Sztainer et al., 2006; Presnell, Stice, Seidel, \& Madeley, 2009; Stice \& Bearman, 2001). Likewise, long-term weight loss is difficult to achieve (Hall, 2010; MacLean et al., 2015) and a cycle of dieting and weight regain may damage mental health. While the majority of included studies did not control for these variables, two studies demonstrated that both higher perceived and actual weight were associated with engaging in unhealthy weight control behaviours (such as restrictive dieting, laxative use, and vomiting), which were subsequently associated with poorer mental health indicated by depressed mood and suicidal ideation (D. S. Kim et al., 2009; D. S. Kim et al., 2008). However across these and other studies, the relationship between perceived overweight and poorer mental health remained significant when controlling for unhealthy weight control behaviours (Eaton et al., 2005; D. S. Kim et al., 2009; D. S. Kim et al., 2008; for adolescent girls only in Lim \& Kim, 2017) and when controlling for selfreported attempts to lose weight in adolescent girls (Yuan, 2007, 2012). It is also possible that the association between perceived overweight and poor mental health is attributable to different mechanisms in individuals of different weight status. For example, a previous systematic review concluded that there was strong evidence for an association between perceived overweight and unhealthy weight control behaviours in individuals with objectively 'normal' weight, whereas the evidence for this association in participants with overweight or obesity was less consistent (Haynes et al., 2018). The association between perceived overweight and mental health may therefore be driven by factors associated with the development of unhealthy weight control such as a high perceived importance of body weight/shape or body dissatisfaction among individuals who are not categorised as overweight (Linde, Wall, Haines, \& Neumark-Sztainer, 2009). Further research is needed to elucidate the mechanisms responsible for the association between perceived overweight and mental health in general, and across different objective weight status categories. An understanding of the mechanisms of these relationships may inform better targeted interventions to buffer against poor mental health.

The results of the present review also have implications for theoretical understandings of how the psychological experience of overweight might contribute to further weight gain. The cyclic obesity/ weight-based stigma (COBWEBS) model proposes that individuals with 
overweight or obesity can be susceptible to experiencing social identity threat as a result of concerns over being stigmatised, which can in turn lead to psychological distress, and further weight gain (Tomiyama, 2014). Our results support the proposition that an individual need not be objectively overweight to enter this cycle: poorer mental health is associated with perceived overweight regardless of objective weight status.

The results of the present work have implications for obesity policies, adding to mounting evidence that suggests that being aware of one's overweight status may be more harmful than helpful (Haynes et al., 2018; Robinson, Haynes, Sutin, \& Daly, 2017; Thurston et al., 2017). Although adults with overweight are more likely to incorrectly perceive their weight as 'about right' than those with obesity, a large number of adults with obesity underestimate their weight status (Johnson et al., 2008; Johnson, Beeken, Croker, \& Wardle, 2014). Large-scale programs which involve screening and providing weight status feedback with the aim of promoting weight loss in individuals with overweight or obesity have been implemented in schools and primary-care in several countries including the UK, USA, and Korea $(\mathrm{H}$. Kim et al., 2017; Moyer, 2012; NHS, n.d; NICE, 2014). However, the results of a recent systematic review cast doubt on the assumption underlying this approach: while perceived overweight was associated with trying to lose weight, it was also associated with greater weight gain over time (Haynes et al., 2018). The present findings add to this evidence by suggesting that being aware of one's overweight status may also be detrimental to mental health, and that furthermore, perceived weight may even account for the association between objective overweight and poor mental health. However, the body of evidence reviewed here was purely observational, highlighting a clear need for thorough evaluation of the impact of programs notifying individuals of their weight status. It is essential that this evaluation consider both the intended effects of such screening programs in terms of promoting healthy behaviour change and weight loss, as well as potential unintended ramifications for mental health.

This work presents the first quantitative synthesis of the evidence for the associations between perceived overweight and depressive symptoms and suicidality. A strength of our review methodology is that we only included effects that were adjusted for or stratified by objective weight status or BMI, which could confound the relationship between perceived overweight and mental health. Few eligible studies controlled for other potential eating and weight-related confounds such as repeated attempts at weight loss, or disordered eating or weight control behaviours. These variables should be taken into account in future research as they may partially explain the relationship between perceived or actual weight status and mental health. Most included studies were of moderate to high quality, and a broadly consistent pattern of results was observed when analyses were restricted to subsets of studies with the most stringent methodology and measurement of clinically-significant outcomes. However, some caution is needed in interpreting the effect sizes from our meta-analyses, as there was a substantial degree of heterogeneity which warrants further exploration of additional moderators. Further, the majority of effects extracted for the present review were from child or adolescent samples (84\%). Although age group did not moderate effects, given that UK clinical practice guidelines promote monitoring and notifying adult primary care patients of their weight the importance of future research on the effects of self-perceived weight status amongst adults should not be neglected (NICE, 2014).

\section{Role of funding sources}

ER's salary was supported by the Medical Research Council (MR/ N000218/1) and Economic Social Research Council (ES/N00034X/1). ER has previously received research funding from Unilever and the American Beverage Association. ARS was supported by a grant from the Eunice Kennedy Shriver National Institute of Child Health and Human Development (1R15HD083947). The funding sources had no role in the study design, collection, analysis, or interpretation of the data, writing the manuscript, or the decision to submit the paper for publication.

\section{Contributors}

AH and ER designed the study. AH wrote the protocol and all authors contributed to and approved the final protocol. AH and IK conducted literature screening and data extraction. $\mathrm{AH}$ conducted the statistical analysis and wrote the first draft of the manuscript. All authors contributed to and have approved the final manuscript.

\section{Conflict of Interest Statement}

All authors declare that they have no conflicts of interest.

\section{Acknowledgments}

We are grateful to Theresa Paumen, Chloe Thompson, Rebecca Bianchi, Maria Huber, and Emily Crowne for research assistance.

\section{Appendix A. Supplementary data}

Supplementary data to this article can be found online at https:// doi.org/10.1016/j.cpr.2019.101753.

\section{References}

Almond, D., Lee, A., \& Schwartz, A. E. (2016). Impacts of classifying New York City students as overweight. Proceedings of the National Academy of Sciences, 113(13), 3488-3491. https://doi.org/10.1073/pnas.1518443113.

Armstrong, B., Westen, S. C., \& Janicke, D. M. (2014). The role of overweight perception and depressive symptoms in child and adolescent unhealthy weight control behaviors: a mediation model. Journal of Pediatric Psychology, 39(3), 340-348 jpepsy/ jst091*.

Atlantis, E., \& Baker, M. (2008). Obesity effects on depression: systematic review of epidemiological studies. International Journal of Obesity, 32(6), 881.

Baumeister, R. F., \& Leary, M. R. (1995). The need to belong: desire for interpersonal attachments as a fundamental human motivation. Psychological Bulletin, 117(3), 497.

BeLue, R., Francis, L. A., \& Colaco, B. (2009). Mental health problems and overweight in a nationally representative sample of adolescents: effects of race and ethnicity. Pediatrics, 123(2), 697-702.

Blaine, B. (2008). Does Depression Cause Obesity? Journal of Health Psychology, 13(8), 1190-1197. https://doi.org/10.1177/1359105308095977.

ter Bogt, T. F., van Dorsselaer, S. A., Monshouwer, K., Verdurmen, J. E., Engels, R. C., \& Vollebergh, W. A. (2006). Body mass index and body weight perception as risk factors for internalizing and externalizing problem behavior among adolescents. The Journal of Adolescent Health, 39(1), 27-34. https://doi.org/10.1016/j.jadohealth.2005.09. $007 *$.

Brewis, A. A., SturtzSreetharan, C., \& Wutich, A. (2018). Obesity stigma as a globalizing health challenge. Globalization and Health, 14(1), 20. https://doi.org/10.1186/ s12992-018-0337-x.

Brewis, A. A., Wutich, A., Falletta-Cowden, A., \& Rodriguez-Soto, I. (2011). Body Norms and Fat Stigma in Global Perspective. Current Anthropology, 52(2), 269-276. https:// doi.org/10.1086/659309.

van den Broek, N., Treur, J. L., Larsen, J. K., Verhagen, M., Verweij, K. J. H., \& Vink, J. M. (2018). Causal associations between body mass index and mental health: a Mendelian randomisation study. Journal of Epidemiology and Community Health, 72(8), 708. https://doi.org/10.1136/jech-2017-210000.

Brown, D. R., \& Blanton, C. J. (2002). Physical activity, sports participation, and suicidal behavior among college students. Medicine and Science in Sports and Exercise, 34(7), 1087-1096. https://doi.org/10.1097/00005768-200207000-00006 *.

Brug, J., Wammes, B., Kremers, S., Giskes, K., \& Oenema, A. (2006). Underestimation and overestimation of personal weight status: associations with socio-demographic characteristics and weight maintenance intentions. Journal of Human Nutrition and Dietetics, 19(4), 253-262.

Byeon, H. (2013). Relationship between self-perception of weight and depression experience in Korean adolescents. Advanced Science and Technology Letters, 40, 66-69. https://doi.org/10.14257/astl.2013.40.15 *.

Byeon, H. (2015). Association between weight misperception patterns and depressive symptoms in Korean young adolescents: National cross-sectional study. PLoS One, 10(8), https://doi.org/10.1371/journal.pone.0131322*

Carr, D., \& Friedman, M. A. (2005). Is obesity stigmatizing? body weight, perceived discrimination, and psychological well-being in the united states. Journal of Health and Social Behavior, 46(3), 244-259. https://doi.org/10.1177/ 002214650504600303.

Ciciurkaite, G., \& Perry, B. L. (2018). Body weight, perceived weight stigma and mental health among women at the intersection of race/ethnicity and socioeconomic status: insights from the modified labelling approach. Sociology of Health \& Illness, 40(1), 18-37. https://doi.org/10.1111/1467-9566.12619.

Crandall, C. S., D'Anello, S., Sakalli, N., Lazarus, E., Nejtardt, G. W., \& Feather, N. (2001). An attribution-value model of prejudice: Anti-fat attitudes in six nations. Personality 
and Social Psychology Bulletin, 27(1), 30-37.

Crandall, C. S., \& Martinez, R. (1996). Culture, Ideology, and Antifat Attitudes. Personality and Social Psychology Bulletin, 22(11), 1165-1176. https://doi.org/10.1177/ 01461672962211007.

Crystal, D. S., Watanabe, H., \& Chen, R. S. (2000). Reactions to Morphological Deviance: A Comparison of Japanese and American Children and Adolescents. Social Development, 9(1), 40-61. https://doi.org/10.1111/1467-9507.00110.

Daly, M., Robinson, E., \& Sutin, A. R. (2017). Does knowing hurt? Perceiving oneself as overweight predicts future physical health and well-being. Psychological Science, 28(7), 872-881. https://doi.org/10.1177/0956797617696311 *.

Donker, T., van Straten, A., Marks, I., \& Cuijpers, P. (2010). Brief self-rated screening for depression on the Internet. Journal of Affective Disorders, 122(3), 253-259 https://doi. org/10.1016/j.jad.2009.07.013.

Duncan, D. T., Wolin, K. Y., Scharoun-Lee, M., Ding, E. L., Warner, E. T., \& Bennett, G. G. (2011). Does perception equal reality? Weight misperception in relation to weightrelated attitudes and behaviors among overweight and obese US adults. International Journal of Behavioral Nutrition and Physical Activity, 8. https://doi.org/10.1186/14795868-8-20.

Duval, S., \& Tweedie, R. (2000). Trim and Fill: A Simple Funnel-Plot-Based Method of Testing and Adjusting for Publication Bias in Meta-Analysis. Biometrics, 56(2), 455-463. https://doi.org/10.1111/j.0006-341X.2000.00455.x.

Eaton, D. K., Lowry, R., Brener, N. D., Galuska, D. A., \& Crosby, A. E. (2005). Associations of body mass index and perceived weight with suicide ideation and suicide attempts among US high school students. Archives of Pediatrics \& Adolescent Medicine, 159(6), 513-519. https://doi.org/10.1001/archpedi.159.6.513 *.

Everaert, J., Podina, I. R., \& Koster, E. H. W. (2017). A comprehensive meta-analysis of interpretation biases in depression. Clinical Psychology Review, 58, 33-48 https://doi. org/10.1016/j.cpr.2017.09.005.

Faith, M. S., Butryn, M., Wadden, T. A., Fabricatore, A., Nguyen, A. M., \& Heymsfield, S. B. (2011). Evidence for prospective associations among depression and obesity in population-based studies. Obesity Reviews, 12(5), e438-e453. https://doi.org/10. 1111/j.1467-789X.2010.00843.x

Foti, K., \& Lowry, R. (2010). Trends in perceived overweight status among overweight and nonoverweight adolescents. Archives of Pediatrics \& Adolescent Medicine, 164(7), 636-642. https://doi.org/10.1001/archpediatrics.2010.90.

Fredrickson, B. L., \& Roberts, T.-A. (1997). Objectification theory: Toward understanding women's lived experiences and mental health risks. Psychology of Women Quarterly, 21(2), 173-206.

Friedman, M. A., \& Brownell, K. D. (1995). Psychological correlates of obesity: Moving to the next research generation. Psychological Bulletin, 117(1), 3-20. https://doi.org/10. 1037/0033-2909.117.1.3.

Frisco, M. L., Houle, J. N., \& Martin, M. A. (2010). The image in the mirror and the number on the scale: Weight, weight perceptions, and adolescent depressive symptoms. Journal of Health and Social Behavior, 51(2), 215-228. https://doi.org/10.1177/ $0022146510372353 *$

Gaskin, J. L., Pulver, A. J., Branch, K., Kabore, A., James, T., \& Zhang, J. (2013). Perception or reality of body weight: Which matters to the depressive symptoms. Journal of Affective Disorders, 150(2), 350-355. https://doi.org/10.1016/j.jad.2013. $04.017 *$

Hackman, J., Maupin, J., \& Brewis, A. A. (2016). Weight-related stigma is a significan psychosocial stressor in developing countries: Evidence from Guatemala. Social Science \& Medicine, 161, 55-60 https://doi.org/10.1016/j.socscimed.2016.05.032.

Hall, K. D. (2010). Predicting metabolic adaptation, body weight change, and energy intake in humans. American Journal of Physiology. Endocrinology and Metabolism, 298(3), E449-E466. https://doi.org/10.1152/ajpendo.00559.2009.

Hasler, G., Pine, D. S., Kleinbaum, D. G., Gamma, A., Luckenbaugh, D., Ajdacic, V., Angst, J. (2005). Depressive symptoms during childhood and adult obesity: the Zurich Cohort Study. Molecular Psychiatry, 10, 842. https://doi.org/10.1038/sj.mp. 4001671.

Haynes, A., Kersbergen, I., Sutin, A., Daly, M., \& Robinson, E. (2018). A systematic review of the relationship between weight status perceptions and weight-loss attempts, strategies, behaviours, and outcomes. Obesity Reviews. https://doi.org/10.1111/obr. 12634.

Heneghan, H. M., Heinberg, L., Windover, A., Rogula, T., \& Schauer, P. R. (2012) Weighing the evidence for an association between obesity and suicide risk. Surgery for Obesity and Related Diseases, 8(1), 98-107. https://doi.org/10.1016/j.soard.2011.10. 007.

Higgins, E. T. (1987). Self-discrepancy: a theory relating self and affect. Psychological Review, 94(3), 319.

Higgins, J. P. T., Thompson, S. G., Deeks, J. J., \& Altman, D. G. (2003). Measuring inconsistency in meta-analyses. BMJ, 327(7414), 557-560. https://doi.org/10.1136/ bmj.327.7414.557.

Himmelstein, M. S., Incollingo Belsky, A. C., \& Tomiyama, A. J. (2014). The weight of stigma: Cortisol reactivity to manipulated weight stigma. Obesity, 23(2), 368-374. https://doi.org/10.1002/oby.20959.

Himmelstein, M. S., Puhl, R. M., \& Quinn, D. M. (2017). Intersectionality: An Understudied Framework for Addressing Weight Stigma. American Journal of Preventive Medicine, 53(4), 421-431.

Himmelstein, M. S., Puhl, R. M., \& Quinn, D. M. (2018). Weight Stigma in Men: What When, and by Whom? Obesity.. https://doi.org/10.1002/oby.22162.

Hunger, J. M., Major, B., Blodorn, A., \& Miller, C. T. (2015). Weighed Down by Stigma: How Weight-Based Social Identity Threat Contributes to Weight Gain and Poor Health. Social and Personality Psychology Compass, 9(6), 255-268.

Jackson, S. E., Beeken, R. J., \& Wardle, J. (2015). Obesity, perceived weight discrimination, and psychological well-being in older adults in England. Obesity, 23(5), 1105-1111. https://doi.org/10.1002/oby.21052.
Jansen, W., van de Looij-Jansen, P. M., de Wilde, E. J., \& Brug, J. (2008). Feeling fat rather than being fat may be associated with psychological well-being in young Dutch adolescents. The Journal of Adolescent Health, 42(2), 128-136. https://doi.org/10. 1016/j.jadohealth.2007.07.015

Janz, N. K., \& Becker, M. H. (1984). The health belief model: A decade later. Health Education Quarterly, 11(1), 1-47. https://doi.org/10.1177/109019818401100101.

Joanna Briggs Institute (2014). Critical Appraisal Checklist for Analytical Cross Sectional Studies Joanna Briggs Institute Reviewer's Manual (2014 ed.). Australia.

Johnson, F., Beeken, R. J., Croker, H., \& Wardle, J. (2014). Do weight perceptions among obese adults in Great Britain match clinical definitions? Analysis of cross-sectional surveys from 2007 and 2012. BMJ Open, 4(11), e005561. https://doi.org/10.1136/ bmjopen-2014-005561.

Johnson, F., Cooke, L., Croker, H., \& Wardle, J. (2008). Changing perceptions of weight in Great Britain: comparison of two population surveys. BMJ, 337. https://doi.org/10. 1136/bmj.a494.

Jones, C. J., \& Meredith, W. (2000). Developmental paths of psychological health from early adolescence to later adulthood. Psychology and Aging, 15(2), 351.

Keel, P. K., Baxter, M. G., Heatherton, T. F., \& Joiner, T. E., Jr. (2007). A 20-year longitudinal study of body weight, dieting, and eating disorder symptoms. Journal of Abnormal Psychology, 116(2), 422.

Kelly, T., Yang, W., Chen, C. S., Reynolds, K., \& He, J. (2008). Global burden of obesity in 2005 and projections to 2030. International Journal of Obesity, 32, 1431. https://doi. org/10.1038/ijo.2008.102.

Kessler, R. C., Aguilar-Gaxiola, S., Alonso, J., Chatterji, S., Lee, S., Ormel, J., ... Wang, P. S. (2011). The global burden of mental disorders: An update from the WHO World Mental Health (WMH) Surveys. Epidemiologia e Psichiatria Sociale, 18(1), 23-33. https://doi.org/10.1017/S1121189X00001421.

Kim, D. S. (2011). Increasing effect of body weight perception on suicidal ideation among young Korean women: Findings from the Korea National Health and Nutrition Examination Survey 2001 and 2005. Diabetes Metab Syndr Obes, 4, 17-22. https://doi. org/10.2147/DMSOTT.S15456 *.

Kim, D. S., Cho, Y., Cho, S. I., \& Lim, I. S. (2009). Body weight perception, unhealthy weight control behaviors, and suicidal ideation among Korean adolescents. The Journal of School Health, 79(12), 585-592. https://doi.org/10.1111/j.1746-1561. 2009.00452.x *.

Kim, D. S., Kim, H. S., Cho, Y., \& Cho, S. I. (2008). The effects of actual and perceived body weight on unhealthy weight control behaviors and depressed mood among adult women in Seoul, Korea. Journal of Preventive Medicine and Public Health, 41(5), 323-330. https://doi.org/10.3961/jpmph.2008.41.5.323 *.

Kim, H., Lee, S., \& Lim, W. (2017). Knowing Is Not Half the Battle: Impacts of the Nationa Health Screening Program in Korea. Journal of Health Economics, 65, 1-4. https://doi. org/10.1016/j.jhealeco.2019.01.003.

Kinoshita, K., Kinoshita, Y., Shimodera, S., Nishida, A., Inoue, K., Watanabe, N., .. Okazaki, Y. (2012). Not only body weight perception but also body mass index is relevant to suicidal ideation and self-harming behavior in Japanese adolescents. The Journal of Nervous and Mental Disease, 200(4), 305-309. https://doi.org/10.1097/ NMD.0b013e31824cb29b *.

Klaczynski, P. A. (2008). There's something about obesity: Culture, contagion, rationality, and children's responses to drinks "created" by obese children. Journal of Experimental Child Psychology, 99(1), 58-74 https://doi.org/10.1016/j.jecp.2007.08. 005.

Klinitzke, G., Steinig, J., Blüher, M., Kersting, A., \& Wagner, B. (2013). Obesity and suicide risk in adults-A systematic review. Journal of Affective Disorders, 145(3), 277-284. https://doi.org/10.1016/j.jad.2012.07.010.

Lee, E. J. (2017). Body Weight Perception, Mental Health, and Weight Control Behavio in Normal Weight Adolescents: Based on the Korea National Health and Nutrition Examination Survey 2013-2015. Child Health Nurs Res, 23(2), 249-257. https://doi. org/10.4094/chnr.2017.23.2.249*.

Lee, K. M., Seo, M. S., Shim, J. Y., \& Lee, Y. J. (2015). Body weight status misperception and its association with weight control behaviours, depressive mood and psychological distress in nulliparous normal-weight young women. Annals of Human Biology, 42(6), 528-532. https://doi.org/10.3109/03014460.2015.1006139 *.

Lenhart, C. M., Daly, B. P., \& Eichen, D. M. (2011). Is accuracy of weight perception associated with health risk behaviors in a diverse sample of obese adolescents? The Journal of School Nursing, 27(6), 416-423. https://doi.org/10.1177/ 1059840511423381

Lim, Y., \& Kim, B. (2017). Body mass index, body weight perception, and depressed mood in korean adolescents. J Korean Acad Child Adolesc Psychiatry, 28(1), 31-37. https:// doi.org/10.5765/jkacap.2017.28.1.31 *.

Linde, J. A., Wall, M. M., Haines, J., \& Neumark-Sztainer, D. (2009). Predictors of initiation and persistence of unhealthy weight control behaviours in adolescents. International Journal of Behavioral Nutrition and Physical Activity, 6(1), 72

Link, B. G., \& Phelan, J. C. (2001). Conceptualizing stigma. Annual Review of Sociology, 27(1), 363-385.

Lo, W. S., Ho, S. Y., Mak, K. K., Lai, H. K., Lai, Y. K., \& Lam, T. H. (2011). Weight misperception and psychosocial health in normal weight Chinese adolescents. International Journal of Pediatric Obesity, 6(2), 381-389. https://doi.org/10.3109/ 17477166.2010.514342*

Lo, W. S., Ho, S. Y., Mak, K. K., Wong, Y. M., Lai, Y. K., \& Lam, T. H. (2009). Prospective effects of weight perception and weight comments on psychological health among Chinese adolescents. Acta Paediatrica, 98(12), 1959-1964. https://doi.org/10.1111/ j.1651-2227.2009.01472.x *.

Luo, H., Li, J., Zhang, Q., Cao, P., Ren, X., Fang, A., ... Liu, L. (2018). Obesity and the onset of depressive symptoms among middle-aged and older adults in China: evidence from the CHARLS. BMC Public Health, 18(1), 909. https://doi.org/10.1186/ s12889-018-5834-6. 
Luppino, F. S., de Wit, L. M., Bouvy, P. F., Stijnen, T., Cuijpers, P., Penninx, B. W., \& Zitman, F. G. (2010). Overweight, obesity, and depression: a systematic review and meta-analysis of longitudinal studies. Archives of General Psychiatry, 67(3), 220-229. https://doi.org/10.1001/archgenpsychiatry.2010.2.

MacLean, P. S., Wing, R. R., Davidson, T., Epstein, L., Goodpaster, B., Hall, K. D., ... Ryan, D. (2015). NIH working group report: Innovative research to improve maintenance of weight loss. Obesity, 23(1), 7-15. https://doi.org/10.1002/oby.20967.

Major, B., Eliezer, D., \& Rieck, H. (2012). The Psychological Weight of Weight Stigma. Social Psychological and Personality Science, 3(6), 651-658. https://doi.org/10.1177/ 1948550611434400.

Major, B., \& O'Brien, L. T. (2005). The social psychology of stigma. Annual Review of Psychology, 56, 393-421.

Mannan, M., Mamun, A., Doi, S., \& Clavarino, A. (2016). Prospective Associations between Depression and Obesity for Adolescent Males and Females- A Systematic Review and Meta-Analysis of Longitudinal Studies. PLoS One, 11(6), e0157240. https://doi.org/10.1371/journal.pone.0157240.

McKinley, N. M. (1998). Gender Differences in Undergraduates' Body Esteem: The Mediating Effect of Objectified Body Consciousness and Actual/Ideal Weight Discrepancy. Sex Roles, 39(1), 113-123. https://doi.org/10.1023/a:1018834001203.

Miller, C. T., \& Downey, K. T. (1999). A Meta-Analysis of Heavyweight and Self-Esteem. Personality and Social Psychology Review, 3(1), 68-84. https://doi.org/10.1207/ s15327957pspr0301_4.

Moher, D., Liberati, A., Tetzlaff, J., \& Altman, D. G. (2009). Preferred reporting items for systematic reviews and meta-analyses: the PRISMA statement. BMJ, 339. https://doi. org/10.1136/bmj.b2535.

Moyer, V. A. (2012). Screening for and Management of Obesity in adults: U.S. Preventive Services Task Force Recommendation Statement. Annals of Internal Medicine, 157(5), 373-378. https://doi.org/10.7326/0003-4819-157-5-201209040-00475.

Murray, C. J., \& Lopez, A. D. (1996). The global burden of disease: a comprehensive assessment of mortality and disability from diseases, injuries, and risk factors in 1990 and projected to 2020. Harvard University Press.

Must, A., Spadano, J., Coakley, E. H., Field, A. E., Colditz, G., \& Dietz, W. H. (1999). The disease burden associated with overweight and obesity. JAMA, 282(16), 1523-1529.

Neumark-Sztainer, D., Wall, M., Guo, J., Story, M., Haines, J., \& Eisenberg, M. (2006) Obesity, disordered eating, and eating disorders in a longitudinal study of adolescents: how do dieters fare 5 years later? Journal of the American Dietetic Association, 106(4), 559-568 https://doi.org/10.1016/j.jada.2006.01.003.

NHS. The National Child Measurement Programme Retrieved July 2017, from http:// www.nhs.uk/Livewell/childhealth1-5/Pages/ChildMeasurement.aspx.

NICE (2014). Obesity: identification, assessment, and management. Clinical Guideline [CG189]. London.

O'Connor, R. C., \& Nock, M. K. (2014). The psychology of suicidal behaviour. The Lancet Psychiatry, 1(1), 73-85.

Paeratakul, S., White, M. A., Williamson, D. A., Ryan, D. H., \& Bray, G. A. (2002). Sex, Race/Ethnicity, Socioeconomic Status, and BMI in Relation to Self-Perception of Overweight. Obesity Research, 10(5), 345-350. https://doi.org/10.1038/oby 2002.48.

Papadopoulos, S., \& Brennan, L. (2015). Correlates of weight stigma in adults with overweight and obesity: A systematic literature review. Obesity, 23(9), 1743-1760. https://doi.org/10.1002/oby.21187.

Pereira-Miranda, E., Costa, P. R. F., Queiroz, V. A. O., Pereira-Santos, M., \& Santana, M. L. P. (2017). Overweight and Obesity Associated with Higher Depression Prevalence in Adults: A Systematic Review and Meta-Analysis. Journal of the American College of Nutrition, 36(3), 223-233. https://doi.org/10.1080/07315724.2016.1261053.

Perera, S., Eisen, R. B., Dennis, B. B., Bawor, M., Bhatt, M., Bhatnagar, N., ... Samaan, Z. (2016). Body Mass Index Is an Important Predictor for Suicide: Results from a Systematic Review and Meta-Analysis. Suicide \& Life-Threatening Behavior, 46(6), 697-736.

Peters, J. L., Sutton, A. J., Jones, D. R., Abrams, K. R., \& Rushton, L. (2007). Performance of the trim and fill method in the presence of publication bias and between-study heterogeneity. Statistics in Medicine, 26(25), 4544-4562. https://doi.org/10.1002/ sim. 2889.

Presnell, K., Stice, E., Seidel, A., \& Madeley, M. C. (2009). Depression and eating pathology: Prospective reciprocal relations in adolescents. Clinical Psychology \& Psychotherapy, 16(4), 357-365. https://doi.org/10.1002/cpp.630.

Puhl, R. M., \& Brownell, K. D. (2001). Bias, Discrimination, and Obesity. Obesity Research, 9(12), 788-805. https://doi.org/10.1038/oby.2001.108.

Puhl, R. M., \& Brownell, K. D. (2006). Confronting and Coping with Weight Stigma: An Investigation of Overweight and Obese Adults. Obesity, 14(10), 1802-1815. https:// doi.org/10.1038/oby.2006.208.

Puhl, R. M., Latner, J. D., O'Brien, K., Luedicke, J., Danielsdottir, S., \& Forhan, M. (2015). A multinational examination of weight bias: predictors of anti-fat attitudes across four countries. International Journal of Obesity, 39, 1166. https://doi.org/10.1038/ijo. 2015.32 .

Puhl, R. M., \& Suh, Y. (2015). Health Consequences of Weight Stigma: Implications for Obesity Prevention and Treatment. Current Obesity Reports, 4(2), 182-190. https:// doi.org/10.1007/s13679-015-0153-Z.

Quek, Y. H., Tam, W. W. S., Zhang, M. W. B., \& Ho, R. C. M. (2017). Exploring the association between childhood and adolescent obesity and depression: a meta-analysis. Obesity Reviews, 18(7), 742-754. https://doi.org/10.1111/obr.12535.

Rhew, I. C., Simpson, K., Tracy, M., Lymp, J., McCauley, E., Tsuang, D., \& Stoep, A. V. (2010). Criterion validity of the short mood and feelings questionnaire and one- and two-item depression screens in young adolescents. Child and Adolescent Psychiatry and Mental Health, 4(1), 8. https://doi.org/10.1186/1753-2000-4-8.

Roberts, R. E., \& Duong, H. T. (2013). Perceived weight, not obesity, increases risk for major depression among adolescents. Journal of Psychiatric Research, 47(8),
1110-1117. https://doi.org/10.1016/j.jpsychires.2013.03.019*

Robinson, E. (2017). Overweight but unseen: A review of the underestimation of weight status and a visual normalization theory. Obesity Reviews, 18, 1200-1209.

Robinson, E., Haynes, A., Sutin, A., \& Daly, M. (2017). Telling people they are over weight: helpful, harmful or beside the point? International Journal of Obesity, 41, 1160-1161. https://doi.org/10.1038/ijo.2017.85.

Robinson, E., Hunger, J. M., \& Daly, M. (2015). Perceived weight status and risk of weight gain across life in US and UK adults. International Journal of Obesity, 39(12), 1721-1726. https://doi.org/10.1038/ijo.2015.143.

Robinson, E., \& Oldham, M. (2016). Weight status misperceptions among UK adults: the use of self-reported vs. measured BMI. BMC Obesity, 3(1), 1-6. https://doi.org/10 1186/s40608-016-0102-8.

Robinson, E., Sutin, A. R., \& Daly, M. (2016). Perceived Weight Discrimination Mediates the Prospective Relation Between Obesity and Depressive Symptoms in US and UK Adults. Health Psychology, 36(2), 112-121.

Romano, E., Haynes, A., \& Robinson, E. (2018). Weight perception, weight stigma concerns, and overeating. Obesity.. https://doi.org/10.1002/oby.22224.

Schiefelbein, E. L., Mirchandani, G. G., George, G. C., Becker, E. A., Castrucci, B. C., \& Hoelscher, D. M. (2012). Association between depressed mood and perceived weight in middle and high school age students: Texas 2004-2005. Maternal and Child Health Journal, 16(1), 169-176. https://doi.org/10.1007/s10995-010-0733-1 *.

Schmitt, M. T., Branscombe, N. R., Postmes, T., \& Garcia, A. (2014). The consequences of perceived discrimination for psychological well-being: a meta-analytic review. Psychological Bulletin, 140(4), 921.

Schvey, N. A., Puhl, R. M., \& Brownell, K. D. (2011). The Impact of Weight Stigma on Caloric Consumption. Obesity, 19(10), 1957-1962. https://doi.org/10.1038/oby. 2011.204.

Seo, D. C., \& Lee, C. G. (2013). The effect of perceived body weight on suicidal ideation among a representative sample of US adolescents. Journal of Behavioral Medicine, 36(5), 498-507. https://doi.org/10.1007/s10865-012-9444-y *.

Shin, J., Choi, Y., Han, K.-T., Cheon, S.-Y., Kim, J.-H., Lee, S. G., \& Park, E.-C. (2015). The combined effect of subjective body image and body mass index (distorted body weight perception) on suicidal ideation. Journal of Preventive Medicine and Public Health, 48(2), 94-104. https://doi.org/10.3961/jpmph.14.055 *.

Sterne, J. A. C., Bradburn, M. J., \& Egger, M. (2008). Meta-Analysis in Stata ${ }^{\mathrm{TM}}$ Systematic Reviews in Health Care (pp. 347-369). BMJ Publishing Group.

Sterne, J. A. C., \& Harbord, R. M. (2004). Funnel plots in meta-analysis. The Stata Journal, 4, 127-141.

Stice, E., \& Bearman, S. K. (2001). Body-image and eating disturbances prospectively predict increases in depressive symptoms in adolescent girls: a growth curve analysis. Developmental Psychology, 37(5), 597.

Sutin, A. R., \& Terracciano, A. (2015). Body weight misperception in adolescence and incident obesity in young adulthood. Psychological Science, 26(4), 507-511. https:// doi.org/10.1177/0956797614566319.

Sutin, A. R., \& Terracciano, A. (2016). Five-Factor Model Personality Traits and the Objective and Subjective Experience of Body Weight. Journal of Personality, 84(1), 102-112. https://doi.org/10.1111/jopy.12143.

Swahn, M. H., Reynolds, M. R., Tice, M., Miranda-Pierangeli, M. C., Jones, C. R., \& Jones, I. R. (2009). Perceived overweight, BMI, and risk for suicide attempts: findings from the 2007 Youth Risk Behavior Survey. The Journal of Adolescent Health, 45(3), 292-295. https://doi.org/10.1016/j.jadohealth.2009.03.006 *.

Swami, V., Frederick, D. A., Aavik, T., Alcalay, L., Allik, J., Anderson, D., ... ZivcicBecirevic, I. (2010). The Attractive Female Body Weight and Female Body Dissatisfaction in 26 Countries Across 10 World Regions: Results of the International Body Project I. Personality and Social Psychology Bulletin, 36(3), 309-325. https://doi. org/10.1177/0146167209359702.

The Global Burden of Disease 2015 Obesity Collaborators. (2017). Health Effects of Overweight and Obesity in 195 Countries over 25 Years. New England Journal of Medicine, 377(1), 13-27.

Thurston, I. B., Sonneville, K. R., Milliren, C. E., Kamody, R. C., Gooding, H. C., \& Richmond, T. K. (2017). Cross-sectional and prospective examination of weight misperception and depressive symptoms among youth with overweight and obesity. Prev Sci, 18(2), 152-163. https://doi.org/10.1007/s11121-016-0714-8 *.

Ting, W. H., Huang, C. Y., Tu, Y. K., \& Chien, K. L. (2012). Association between weight status and depressive symptoms in adolescents: role of weight perception, weight concern, and dietary restraint. Eur J Pediatr, 171(8), 1247-1255. https://doi.org/10. 1007/s00431-012-1753-1 *

Tomiyama, A. J. (2014). Weight stigma is stressful. A review of evidence for the Cyclic Obesity/Weight-Based Stigma model. Appetite, 82, 8-15.

Tooth, L., Ware, R., Bain, C., Purdie, D. M., \& Dobson, A. (2005). Quality of Reporting of Observational Longitudinal Research. American Journal of Epidemiology, 161(3), 280-288. https://doi.org/10.1093/aje/kwi042.

Vartanian, L. R. (2012). Self-discrepancy theory and body image. In J. K. Thompson, L. M. Schaefer, \& J. E. Menzel (Eds.). Encyclopedia of Body Image and Human Appearance (pp. 711-717). London: UK: Elsevier.

Vittengl, J. R. (2018). Mediation of the bidirectional relations between obesity and depression among women. Psychiatry Research, 264, 254-259 https://doi.org/10.1016/ j.psychres.2018.03.023

Williams, K. D. (2007). Ostracism. Annual Review of Psychology, 58.

Wirth, J. H., \& Williams, K. D. (2009). 'They Don't Like Our Kind': Consequences of Being Ostracized While Possessing a Group Membership. Group Processes \& Intergroup Relations, 12(1), 111-127. https://doi.org/10.1177/1368430208098780.

de Wit, L. M., van Straten, A., van Herten, M., Penninx, B. W., \& Cuijpers, P. (2009). Depression and body mass index, a u-shaped association. BMC Public Health, 9(1), 14. https://doi.org/10.1186/1471-2458-9-14.

World Health Organization. (2016). Global Health Observatory data: overweight and 
obesity Retrieved 8 February 2019, from https://www.who.int/gho/ncd/risk factors/overweight obesity/overweight adolescents/en/

World Health Organization. (2017). Depression and other common mental disorders: Global health estimates Retrieved 8 February 2019, from https://apps.who.int/iris/ bitstream/handle/10665/254610/WHOMSD?sequence $=1$

Wray, N. R., Ripke, S., Mattheisen, M., Trzaskowski, M., Byrne, E. M., Abdellaoui, A., ... the Major Depressive Disorder Working Group of the Psychiatric Genomics, C (2018). Genome-wide association analyses identify 44 risk variants and refine the genetic architecture of major depression. Nature Genetics, 50(5), 668-681. https://doi.org/ 10.1038/s41588-018-0090-3.

Xie, B., Chou, C. P., Spruijt-Metz, D., Reynolds, K., Clark, F., Palmer, P. H., \& Johnson, C. A. (2006). Weight perception, academic performance, and psychological factors in Chinese adolescents. American Journal of Health Behavior, 30(2), 115-124. https:// doi.org/10.5555/ajhb.2006.30.2.115 *.

Yuan, A. S. V. (2007). Gender differences in the relationship of puberty with adolescents' depressive symptoms: Do body perceptions matter? Sex Roles, 57(1-2), 69-80. https://doi.org/10.1007/s11199-007-9212-6 *.

Yuan, A. S. V. (2012). Perceived breast development and adolescent girls' psychological well-being. Sex Roles, 66(11-12), 790-806. https://doi.org/10.1007/s11199-0120138-2*.

Zeller, M. H., Reiter-Purtill, J., Jenkins, T. M., \& Ratcliff, M. B. (2013). Adolescent suicidal behavior across the excess weight status spectrum. Obesity, 21(5), 1039-1045. https://doi.org/10.1002/oby.20084 *.

Zhang, J., Yan, F., Li, Y., \& McKeown, R. E. (2013). Body mass index and suicidal behaviors: A critical review of epidemiological evidence. Journal of Affective Disorders, 148(2), 147-160. https://doi.org/10.1016/j.jad.2012.05.048.

Zhao, M., Zhang, M., Zhou, X., Yang, H., Yang, Y., \& Yang, N. (2012). Weight misperception and its barriers to keep health weight in Chinese children. Acta Paediatrica, 101(12), 550-556. https://doi.org/10.1111/apa.12011. 